\title{
Novel Non-phosphorylated Serine 9/21 GSK3 $\beta / \alpha$ Antibodies: Expanding the Tools for Studying GSK3 Regulation
}

\author{
Tessa Grabinski1 and Nicholas M. Kanaan ${ }^{1,2 *}$ \\ ${ }^{1}$ Department of Translational Science and Molecular Medicine, College of Human Medicine, Michigan State University, \\ Grand Rapids, MI, USA, ${ }^{2}$ Hauenstein Neuroscience Center, Mercy Health Saint Mary's, Grand Rapids, MI, USA
}

Glycogen synthase kinase 3 (GSK3) $\beta$ and $\alpha$ are serine/threonine kinases involved in many biological processes. A primary mechanism of GSK3 activity regulation is phosphorylation of N-terminal serine (S) residues (S9 in GSK3 $\beta$, S21 in GSK3 $\alpha$ ). Phosphorylation is inhibitory to GSK3 kinase activity because the phosphorylated $\mathrm{N}$-terminus acts as a competitive inhibitor for primed substrates. Despite widespread interest in GSK3 across most fields of biology, the research community does not have reagents that specifically react with nonphosphoS9/21 GSK3B/ $\alpha$ (the so-called "active" form). Here, we describe two novel monoclonal antibodies that specifically react with nonphosphoS9/21 GSK3 $\beta / \alpha$ in multiple species (human, mouse, and rat). One of the antibodies is specific for nonphospho-S9 GSK3 $\beta$ (clone 12B2) and one for nonphospho-S9/21 GSK3ß/ $\alpha$ (clone 15C2). These reagents were validated for specificity and reactivity in several biochemical and immunochemical assays, and they show linear detection of nonphosphoS GSK3. Finally, these reagents provide significant

OPEN ACCESS

Edited by:

Shin-ichi Hisanaga, Tokyo Metropolitan University, Japan

Reviewed by:

Francisco G. Wandosell, Centro de Biología Molecular Severo Ochoa (CSIC), Spain Michael Alan Cousin, University of Edinburgh, UK

*Correspondence: Nicholas M. Kanaan nicholas.kanaan@hc.msu.edu

Received: 07 September 2016 Accepted: 02 November 2016 Published: 17 November 2016

Citation:

Grabinski T and Kanaan NM (2016) Novel Non-phosphorylated Serine 9/21 GSK3 $\beta / \alpha$ Antibodies: Expanding the Tools for Studying GSK3 Regulation.

Front. Mol. Neurosci. 9:123. doi: 10.3389/fnmol.2016.00123 advantages in studying GSK3 $\beta$ regulation. We used both antibodies to study the regulation of S9 phosphorylation by Akt and protein phosphatases. We used 12B2 (due to its specificity for GSK3 $\beta$ ) and to demonstrate that protein phosphatase inhibition reduces nonphospho-S9 GSK3 $\beta$ levels and lowers kinase activity within cells. The ability to use the same reagent across biochemical, immunohistological and kinase activity assays provides a powerful approach for studying serine-dependent regulation

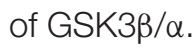

\section{Keywords: glycogen synthase kinase, signal transduction, kinase, phosphorylation, monoclonal antibody}

\section{INTRODUCTION}

Glycogen synthase kinase (GSK) was described in the 80's for its role in regulating glycogen synthase (Embi et al., 1980; Rylatt et al., 1980). GSK3 is a highly conserved serine (S)/threonine (T) kinase and two genes encode the $\alpha$ and $\beta$ paralogs. The primary consensus sequence of GSK3 $\beta$ substrates is S/T-X-X-X-pS/pT, where phosphorylation of the target $\mathrm{S} / \mathrm{T}$ is facilitated by a "priming" phosphate group on a S or T four amino acids downstream (Forde and Dale, 2007; Medina and Wandosell, 2011). The primed residue binds the primed substrate pocket bringing the target $\mathrm{S} / \mathrm{T}$ residue into the kinase domain (Beurel et al., 2015). A number of GSK3 $\beta$ substrates such as glycogen synthase, $\beta$-catenin and tau are phosphorylated by GSK3 $\beta$ after being primed by other kinases (Zhang et al., 1993; Hagen and Vidal-Puig, 2002; Li et al., 2006), but not all GSK3 $\beta$ substrates require priming (Wang et al., 1994b). 
Over 80 proposed GSK3 targets exist (most of which are not exclusive GSK3 substrates) and this kinase plays a role in numerous biological processes such as cell proliferation, cell migration, cell polarization, transcription, glucose regulation, the immune system, and inflammation (Frame and Cohen, 2001; Kim and Kimmel, 2006; Kockeritz et al., 2006; Sutherland, 2011; Beurel et al., 2015). Canonical Wnt signaling, where it phosphorylates $\beta$-catenin to signal the degradation of $\beta$-catenin, is a well-studied GSK3 $\beta$ pathway (Aberle et al., 1997; Chen et al., 2000; McManus et al., 2005). GSK3 $\beta$ also is involved in apoptosis, cancer biology, and several neurodegenerative diseases (Hetman et al., 2000; Hernandez and Avila, 2008; Cadigan and Peifer, 2009; Golpich et al., 2015; Li et al., 2015; O'Leary and Nolan, 2015). With such diverse functions, it is not surprising that GSK3 activity is tightly regulated.

In general, phosphorylation at S9 in GSK3 $\beta$ or S21 in GSK $3 \alpha$ by other kinases and/or autophosphorylation is the prominent regulatory mechanism, but several additional regulatory mechanisms exist (Beurel et al., 2015). S9/S21 phosphorylation leads to inactivation because the N-terminus of GSK3 competitively blocks substrate docking in the primed substrate pocket (Frame et al., 2001) acting as a dominant negative regulator of GSK3 activity, especially against substrates requiring priming. In situ, GSK3 is regulated, at least in part, by phosphorylation at $\mathrm{S} 9$ from Akt leading to reduced activity (Gold et al., 2000; Varea et al., 2010; Majewska and Szeliga, 2016) and protein phosphatases that dephosphorylate S9 leading to increased activity under several biological contexts (Sutherland et al., 1993; Leung-Hagesteijn et al., 2001; Morfini et al., 2004; Lee et al., 2005; Szatmari et al., 2005; Bertrand et al., 2012). However, the lack of reagents that specifically detect nonphospho-S9 (npS9) GSK3 has limited our ability to directly study dephosphorylation of this $\mathrm{N}$-terminal serine. The activity of GSK3 is augmented by the phosphorylation of tyrosine 216 in GSK3 $\beta$ or tyrosine 279 in GSK3 $\alpha$, (Hughes et al., 1993; Frame and Cohen, 2001), but tyrosine phosphorylation appears to be mostly derived from chaperone-dependent autophosphorylation during (or shortly after) translation and stabilizes the enzymes (Wang et al., 1994a; Cole et al., 2004; Lochhead et al., 2006).

Reagents for specifically assessing changes in the pool of "active" GSK3 $\beta / \alpha$ (i.e., npS9/21) do not exist. Currently, researchers rely on the use of phospho-S9 GSK3 $\beta$ or phosphoS21 GSK3 $\alpha$ antibodies for detecting "inactive" enzymes. These approaches only indirectly measure active GSK3 by comparing changes in the ratio of phospho-Ser GSK3 to total GSK3. Moreover, kinase activity assays are available, but the required specificity for GSK3 $\beta$ is not currently possible in lysates. Instead, GSK3 $\beta$ activity assays are performed by immunoprecipitating GSK3 $\beta$ and then measuring activity with GSK3 $\beta$ substrate peptides or proteins (Welsh et al., 1997; Bijur and Jope, 2001; Bowley et al., 2005). Reagents that directly detect the amount of npS9 GSK3 $\beta$ and can be used in GSK3 $\beta$ kinase activity assays would provide obvious advantages to biochemical analyses and allow localization within cells and tissues. Thus, we set out to generate novel monoclonal antibodies against npS9 in GSK3 $\beta$ because of the lack of such reagents, involvement of GSK3 $\beta$ in several processes and the broad interest in GSK3 $\beta$ across many fields.

\section{MATERIALS AND METHODS}

\section{Synthetic GSK3 Peptides}

The GSK3 $\beta$ immunization peptides were synthesized and Keyhole Limpet hemocyanin (KLH) was conjugated to the N-termini by GenScript (Piscataway, NJ, USA). The following peptides were generated using variations within the first 14 amino acids of human GSK3 $\beta$ (Uniprot ID: P49841), (1) N-term KLH npS9 GSK3 $\beta$ peptide: 1-14 GSK3 $\beta$ (KLH${ }^{1}$ MSGRPRTTSFAESC ${ }^{14}$ ), (2) arginine enantiomer npS9 GSK3 $\beta$ peptide (KLH- ${ }^{1}$ MSG[d-R]PRTTSFAESC ${ }^{14}$ ) and (3) tandem npS9 GSK3 $\beta$ peptide (KLH- ${ }^{4}$ RPRTTSFAES $^{13} /{ }^{4}$ RPRTTSFAES $^{13}$ ). These KLH-peptide reagents were $>90 \%$ pure and stocks at $2 \mathrm{mg} / \mathrm{ml}$ were diluted in $\mathrm{H}_{2} \mathrm{O}$ and stored at $-20^{\circ} \mathrm{C}$ until used for immunizations as described below. The following four peptides GSK3 $\beta$ and $\alpha$ screening peptides were used for screening during monoclonal antibody production, (1) npS9 GSK3 $\beta$ ( ${ }^{1}$ MSGRPRTTSFAESCKPVQQPSAFGS $\left.{ }^{25}\right)$, (2) pS9 GSK3 $\beta\left({ }^{1}\right.$ MSGRPRTT[pS]FAESCKPVQQPSAFGS $\left.{ }^{25}\right)$, (3) npS21 GSK3 $\alpha\left({ }^{10}\right.$ GPGGSGRARTSSFAEPGGG $\left.{ }^{28}\right)$ and (4) pS21 GSK3 $\alpha$ $\left({ }^{10} \mathrm{GPGGSGRARTS}[\mathrm{pS}]\right.$ FAEPGGG $\left.{ }^{28}\right)$. These peptides were $>90 \%$ pure and stocks at $1 \mathrm{mg} / \mathrm{ml}$ diluted in $\mathrm{H}_{2} \mathrm{O}$ were stored at $-20^{\circ} \mathrm{C}$ until used in assays as indicated below.

\section{Animal and Human Subjects}

Three-month-old BALB/c female mice were used for immunizations. A male C57BL/6J wild-type mouse and male Fisher 344 rat were perfused with $0.9 \%$ saline containing heparin for fresh tissue samples. A male Fisher 344 rat was perfused for fixed tissue as described Grabinski et al. (2015). Timed-pregnant female Sprague Dawley rats were used to obtain E18 fetal cortical cells for primary neuron cultures as described Grabinski et al. (2015). All studies involving animals were conducted in compliance with federal, state and institutional guidelines and approved by the Michigan State University Institutional Animal Care and Use Committee.

Fresh frozen tissue from the frontal cortex of an aged, nondemented case (sex: male, age: 75 years, post-mortem interval: $2.5 \mathrm{~h}$ ) was used for biochemical analyses, and fixed tissue from an aged non-demented case was used (sex: male, age: 80 years, post-mortem interval: $3.25 \mathrm{~h}$ ) for the immunohistochemical analysis. The Michigan State University Institutional Review Board approved all post-mortem human tissue studies for human subject's exemption. All of the samples were de-identified and obtained through the Alzheimer's Disease Research Center at Banner Sun Health Research Institute (Beach et al., 2015).

\section{Monoclonal Antibody Production}

Animals received injections of the N-terminal peptide, enantiomer peptide, tandem repeat peptide, or a mixture of all three peptides (200 $\mu$ g peptide) every 3 weeks and serum was collected 3 days after the indicated immunizations to determine antibody titer. Once serum titers showed above-background 
signal at $\geq 1: 51,200$ dilution, the animal was boosted again and 3 days later used for the fusion procedure. Hybridoma fusion techniques similar to those described previously were used to create monoclonal antibodies (Binder et al., 1985). Cultures were screened for reactivity against npS9 GSK3 $\beta$, pS9 GSK3 $\beta$, pS9 GSK $3 \beta$ and pS21 GSK3 $\beta$ screening peptides by indirect ELISAs 7-10 days after plating. Cultures that were positive (i.e., typically absorbance $>1.0$ ) were expanded, screened again and then plated into 96-well ( $\sim 1$ cell/well for first clone plating). Clones were screened again, and the strongest wells were expanded in medium consisting of RPMI-1640 supplemented with 1x HT (11067-030, Thermo, Waltham, MA, USA), 10\% Fetal bovine serum, $5 \%$ L-Glutamine, $1 \%$ sodium pyruvate, and $1 \%$ penicillinstreptomycin. Cells were subcloned following this process at least three times and we require $>95 \%$ of all wells are positive in ELISAs. The third subclones were subjected to freeze/thaw cycles (Hybridoma Freezing Medium: RPMI-1640, 10\% FBS, 5\% L-Glutamine, $1 \%$ sodium pyruvate, $1 \%$ penicillin-streptomycin and $5 \%$ DMSO) for a total of three times to establish stability upon liquid nitrogen freezing and retrieval. Antibody isotypes were determined using the IsoStrip Mouse Monoclonal Antibody Isotyping Kit (11493027001, Roche) and mycoplasma testing was performed using the Mycoplasma PCR ELISA kit (11663925910, Roche). Once the clones were verified as clean, stable and positive the antibodies were purified.

Each antibody was produced using CELLine 350 bioreactors (Integra Biosciences, Hudson, NH, USA) according to the manufacturer's instructions. Culture supernatants were dialyzed overnight in $1.5 \mathrm{M}$ glycine, $3 \mathrm{M} \mathrm{NaCl}$ buffer, $\mathrm{pH} 8.9$ (Protein A buffer) using dialysis tubing (PI68100, Thermo). Dialyzed culture supernatant was centrifuged at $12,000 \times g$ for $20 \mathrm{~min}$ and filtered ( $5 \mu \mathrm{m}$ pore filter) and purified using rProtein A Sepharose Fast Flow resin (17-1279-01, GE Healthcare, Pittsburgh, PA, USA). The antibodies were eluted using $0.1 \mathrm{M}$ citric acid starting at $\mathrm{pH}$ 6, followed by $\mathrm{pH} 5, \mathrm{pH} 4$, and $\mathrm{pH} 3$ (10 ml each). Fractions were collected $(5 \mathrm{ml})$, run on $4-20 \%$ Tris- $\mathrm{HCl}$ Criterion gels (5671093, BioRad, Hercules, CA, USA) and stained by Coomassie. Fractions containing IgGs were pooled and concentrated in an Amicon Ultra Centrifugal Unit (UFC90-30-24, Thermo) and dialyzed overnight in antibody storage buffer (10 mM HEPES, $500 \mathrm{mM} \mathrm{NaCl}, 50 \%$ Glycerol). Concentrations were measured using A280 (extinction coefficient of 13.7) and antibodies were adjusted to $1 \mathrm{mg} / \mathrm{ml}$, aliquoted and stored at $-80^{\circ} \mathrm{C}$.

\section{Indirect ELISAs}

Indirect ELISAs were performed to determine the binding affinity and specificity of each of the antibodies for non phospho and phospho GSK3 $\beta$ and GSK3 $\alpha$ peptides as described Kanaan et al. (2011). For the antibody titer ELISAs, $50 \mu \mathrm{l}$ of the GSK3 screening peptides (without $\mathrm{KLH}$ ) were diluted to $2 \mathrm{ng} / \mu \mathrm{l}$ in a borate saline solution ( $100 \mathrm{mM}$ boric acid, $25 \mathrm{mM}$ sodium tetraborate decahydrate, $75 \mathrm{mM} \mathrm{NaCl}, 250 \mu \mathrm{M}$ thimerosal) and wells (Corning, \#3590) were coated for $1 \mathrm{~h}$. Between all steps, wells were washed with ELISA wash solution $(100 \mathrm{mM}$ boric acid, $25 \mathrm{mM}$ sodium tetraborate decahydrate, $75 \mathrm{mM}$ $\mathrm{NaCl}, 250 \mu \mathrm{M}$ thimerosal, $0.4 \%$ bovine serum albumin and $0.1 \%$ tween-20; $200 \mu \mathrm{l} /$ well). Wells were blocked with $200 \mu \mathrm{l}$
5\% non-fat dry milk made in ELISA wash solution (blocking buffer) for $1 \mathrm{~h}$. The purified GSK3 antibodies were serially diluted in blocking buffer at a range from 1:400 $(2500 \mathrm{ng} / \mathrm{ml}$ or $16.7 \mathrm{nM})$ to $1: 819,200(1.22 \mathrm{ng} / \mathrm{ml}$ or $6.7 \mathrm{pM})$ and incubated for 2 h. Goat anti-mouse HRP conjugated antibody (115-035-003, Jackson ImmunoResearch, West Grove, PA, USA) was added to each well at a dilution of 1:5,000 for $1 \mathrm{~h}$. Reactivity was detected by adding 3,3',5,5' tetramethylbenzidine substrate (T0440, Sigma Aldrich, St. Louis, MO, USA) to each well and incubated for approximately $8 \mathrm{~min}$. Reactions were quenched with $50 \mu 13.6 \%$ $\mathrm{H}_{2} \mathrm{SO}_{4}$ and then the absorbance at $450 \mathrm{~nm}$. Blank wells were used to obtain background absorbance, which was removed from sample signals. For antibody specificity ELISAs, the assays were run as described above with the exception that the plates were coated with a wide range of either npS9 GSK3 $\beta$, pS GSK3 $\beta$, npS21 GSK3 $\alpha$, or pS21 GSK3 $\alpha$ peptides $(0-6.4 \mu \mathrm{g} /$ well $)$. The peptides were detected using 12B2 (2 nM) or 15C2 (1 nM) primary antibodies and signals were detected and analyzed as above. Finally, we confirmed the presence of phosphorylation at S9 in the pS9 GSK3 $\beta$ peptide (well coated with $50 \mu \mathrm{l}$ at $2 \mathrm{ng} / \mu \mathrm{l}$ ) using the phosphoS9 GSK3 $\beta$ primary antibody $(1: 1,000 ; 9323$, Cell Signaling).

\section{Cell Culture}

Primary neurons from E18 rat cortex were cultured for 8 days as described previously (Grabinski et al., 2015). Human embryonic kidney (HEK) 293T cells (CRL-3216, ATCC) were grown in DMEM (11995-065, Thermo) supplemented with 5\% FBS and $1 \%$ penicillin/streptomycin (15140-122, Thermo). Human neuroblastoma SH-SY5Y cells (CRL-2266, ATCC) were grown in Ham's F-12 medium (11765-054, Thermo) mixed with Minimum Essential Medium (11095-080, Thermo) at a ratio of $1: 1$ and supplemented with 5\% FBS and $1 \%$ penicillin/streptomycin. Human glioblastoma U373 cells and mouse neuroblastoma Neuro-2A cells were grown in DMEM/Ham's F12 (10-090$\mathrm{CV}$, Corning) supplemented with $10 \% \mathrm{FBS}, 2 \mathrm{mM}$ L-glutamine (25030-081, Thermo), 1\% MEM Non-Essential Amino Acids (11140-050, Thermo), and $1 \mathrm{mM}$ sodium pyruvate $(25000 \mathrm{CI}$, Corning). Cells were collected and processed for the specific assays as outlined below.

\section{siRNA Knockdown}

HEK293T cells were plated in a 24-well plate at a density of 60,000 cells/well in $400 \mu \mathrm{l}$ growth medium without antibiotics (DMEM (11995-065, Thermo) supplemented with 5\% FBS) 1 day prior to transfection. HEK293T cells were transfected with either the human GSK3 $\beta$ Stealth primer set (1299001-VHS40279, Thermo), the human GSK3 $\alpha$ Stealth primer set (1299001-HSS104518, Thermo), the human GAPDH Stealth control (12935140, Thermo), or the medium GC siRNA negative control (12935300, Thermo) constructs according to manufacturer's protocol. The GAPDH siRNA controls for expression of a functional siRNA against an unrelated target, and the medium GC siRNA is an additional control for non-specific effects. The siRNA constructs were diluted to $100 \mathrm{pM}$ for GSK3 $\alpha, 100 \mathrm{pM}$ for GSK3 $\beta, 40 \mathrm{nM}$ for GAPDH or $10 \mathrm{nM}$ for medium GC in $50 \mu \mathrm{l}$ OPTI-MEM (31985070, Thermo). Lipofectamine 2000 (11668-027, Thermo) was 
mixed at a ratio of 1-50 $\mu$ l OPTI-MEM and incubated at room temperature for $15 \mathrm{~min}$. Then, the siRNAs and Lipofectamine 2000 were combined and incubated at room temperature for $15 \mathrm{~min}$. After the incubation, the reagents were added to the cells (100 $\mu \mathrm{l} /$ well) and incubated for $48 \mathrm{~h}$ before collecting the cells for Western blotting and immunocytofluorescence as described below.

\section{B2 and 15C2 Antibody Immunoprecipitations}

Immunoprecipitations were performed by conjugating either $12 \mathrm{~B} 2,15 \mathrm{C} 2$ or a non-immune mouse IgG to NHS Magnetic Sepharose beads according to the manufacturer's instructions (28944009, GE Healthcare). Magnetic beads were prepared by briefly equilibrating $25 \mu \mathrm{l}$ of the bead slurry into ice cold $1 \mathrm{mM}$ $\mathrm{HCl}$, then immediately removing equilibration buffer and adding $200 \mu \mathrm{l}$ of the antibody at $25 \mathrm{ng} / \mu \mathrm{l}$ ( $5 \mu \mathrm{g}$ total antibody diluted in phosphate buffered saline: $137 \mathrm{mM}, \mathrm{NaCl}, 2.68 \mathrm{mM} \mathrm{KCl}$, $10 \mathrm{mM} \mathrm{Na}_{2} \mathrm{HPO}_{4}, 1.76 \mathrm{mM} \mathrm{KH}_{2} \mathrm{PO}_{4}, \mathrm{pH}$ 7.4). The antibodies were bound to the beads during a $40 \mathrm{~min}$ incubation at room temperature with end over end mixing. Residual NHS active groups were blocked following a series of washes and incubations with two separate reagents. Beads were washed with $500 \mu \mathrm{l}$ blocking buffer A (50 mM tris- $\mathrm{HCl}, 1 \mathrm{M} \mathrm{NaCl}, \mathrm{pH} 8.0$ ), followed by washing with $500 \mu$ l blocking buffer B $(50 \mathrm{mM}$ glycine- $\mathrm{HCl}$, $1 \mathrm{M} \mathrm{NaCl}, \mathrm{pH} 3.0$ ), followed by incubation in $500 \mu \mathrm{l}$ blocking buffer $\mathrm{A}$ for $15 \mathrm{~min}$ with end over end mixing. Another series of washes occurred starting with blocking buffer B, followed by blocking buffer A, and then blocking buffer B. After removing the final blocking buffer B the IgG-bound beads were resuspended in $500 \mu \mathrm{TBS}$ and transferred to a new tube. HEK293T cells were collected in lysis buffer (20 mM tris, pH 7.5, 2.5mM DTT, $1 \%$ Triton $\mathrm{X}-100,300 \mathrm{mM} \mathrm{NaCl}$ )), sonicated and spun at $12,000 \times g$ for $10 \mathrm{~min}$ to remove debris and the supernatant was used for the immunoprecipitations. The beads were incubated with $500 \mu \mathrm{g}$ total protein of HEK293T lysate with end over end mixing for $1 \mathrm{~h}$ at room temperature. Lysate samples prior to incubation with the beads were reserved as the "Input" sample for western blotting. After samples were incubated with beads, the unbound sample was removed and saved for use as the "Post-IP" sample for western blotting. The beads were washed $5 \mathrm{x}$ with $500 \mu \mathrm{l}$ TBS before transferring to a new tube. The final wash was removed and beads were resuspended in $25 \mu 12 \mathrm{x}$ Laemmli sample buffer. SDS-PAGE and western blotting were done using $50 \mu \mathrm{g}$ "Input" and "Post-IP" samples, and $12.5 \mu \mathrm{l}$ of each IP sample was used for the "12B2-IP," "15C2-IP" and "Ms IgG-IP" samples. The IP experiments were repeated three independent times and western blots (12B2, 15C2, and IgG control) were probed with rabbit anti-GSK3 $\alpha / \beta$ total antibody $(1: 2,000,5676$, Cell Signaling) and imaged as described below.

\section{Western Blotting}

Purified npS9 GSK3 antibodies were validated with recombinant GSK3 $\beta$ and $\alpha$ protein and brain lysates from human, mouse and rats (Kanaan et al., 2011, 2012). Recombinant protein samples were prepared by using 300 ng GSK3 $\beta$ alone (His-tagged,
PV3365, Thermo, Waltham, MA, USA) or GSK3 $\alpha$ alone (GSTtagged, PV6126, Thermo, Waltham, MA, USA), GSK3 $\beta$ or $\alpha$ incubated with alkaline phosphatase (6 U per reaction; EF0651, Fermentas, Waltham, MA, USA) for $4 \mathrm{~h}$ at $30^{\circ} \mathrm{C}$ to create a non-phosphorylated GSK3 sample, and GSK3 $\beta$ or $\alpha$ incubated with $2 \mu \mathrm{g}$ Akt (14-276, Millipore, Billerica, MA, USA) and ATP $(400 \mu \mathrm{M})$ for $4 \mathrm{hrs}$ at $30^{\circ} \mathrm{C}$ to create a phosphorylated Ser GSK3 sample. The samples were brought to a final concentration of $8.33 \mathrm{ng} / \mu \mathrm{l}$ in $2 \mathrm{x}$ Laemmli sample buffer at $98^{\circ} \mathrm{C}$ for $10 \mathrm{~min}$. Human, mouse, and rat frontal cortex homogenates and cell culture lysates (primary neurons were grown for 8 days at 45,000 cells $/ \mathrm{cm}^{2}$ and cell lines were collected when $\sim 80-90 \%$ confluent) were prepared by sonicating samples in lysis buffer $(20 \mathrm{mM}$ Tris, pH 7.5, $2.5 \mathrm{mM}$ DTT, $300 \mathrm{mM} \mathrm{NaCl}, 1 \%$ Triton X-100). Samples were centrifuged at $12,000 \times g$ for $10 \mathrm{~min}$ at $4^{\circ} \mathrm{C}$ and supernatants collected. Total protein concentrations were determined using the Bradford protein assay (500-0006, BioRad, Hercules, CA, USA).

Recombinant GSK3 samples were loaded at $50 \mathrm{ng} /$ lane, while the brain lysates and cell culture lysates were loaded at $50 \mu \mathrm{g} / \mathrm{lane}$ and separated using SDS-PAGE on 4-20\% Tris-HCl Criterion gels (BioRad). Proteins were transferred onto PVDF membrane (IPFL00010, Millipore, Billerica, MA, USA) and probed with either $12 \mathrm{~B} 2(1: 1,000)$ or $15 \mathrm{C} 2(1: 3,000)$ and total GSK3 $\alpha / \beta$ (1:2,000; 5676, Cell Signaling), or with pS9 GSK3 $\beta$ (1:1,000; 9323, Cell Signaling) and Ms total GSK3 $\beta$ (1:2,000 9832, Cell Signaling) antibodies diluted in 5\% non-fat dry milk in tris buffered saline (TBS, 0.5 M Tris, 1.5 M sodium chloride, $\mathrm{pH}$ 7.4) overnight at $4^{\circ} \mathrm{C}$. Brain lysate blots were also probed with anti-GAPDH antibody $(1: 2,000 ; 5174$, Cell Signaling) for a loading control. The following day the blots were incubated for $1 \mathrm{~h}$ at with IRDye 800CW goat anti-mouse IgG $(\mathrm{H}+\mathrm{L})(1: 20,000$; 926-32210, LiCor Biosciences, Lincoln, NE, USA) and IRDye 680LT goat antirabbit IgG ( $\mathrm{H}+\mathrm{L})$ (1:20,000; 926-68021, LiCor Biosciences) for $12 \mathrm{~B} 2$ and $15 \mathrm{C} 2$ antibody blots, or IRDye 680LT goat antimouse IgG $(\mathrm{H}+\mathrm{L})$ (1:20,000; 926-68020, LiCor Biosciences) and IRDye 800CW goat anti-rabbit IgG $(H+\mathrm{L})$ (1:20,000; 925-32211, LiCor Biosciences) for pS9 GSK3 $\beta$ blots. Immunoblots from the Akt inhibitor and protein phosphatase inhibitor experiments (see below) were probed with total Akt $(1: 2,000 ; 2920$, Cell Signaling) and either phospho-Thr308 Akt (1:1000; 13038, Cell Signaling) or phospho-Ser473 Akt (1:2,000; 4060, Cell Signaling) antibodies, and detected with IRDye 680LT goat anti-mouse IgG $(\mathrm{H}+\mathrm{L})$ and IRDye $800 \mathrm{CW}$ goat anti-rabbit $\operatorname{IgG}(\mathrm{H}+\mathrm{L})$ as above. Then blots were imaged using a Licor Odyssey system. Band signal intensities were quantified using ImageStudio software (v5.2.5, LiCor Biosciences). The signals for 12B2, 15C2 and the pS9 GSK3 $\beta$ antibodies were normalized to total GSK3 signal in the recombinant GSK3 blots.

\section{Cell Culture Immunocytofluorescence}

Primary neurons from E18 rat cortex, HEK293T and SH-SY5Y cells were plated at 30,000 cells/well in 8-well chamber slides coated with poly-D-lysine (to enhance cell adherence). Neurons were grown for 8 days, while HEK293T and SH-SY5Y cells were grown for 2 days before being fixed for $20 \mathrm{~min}$ at room temperature using $4 \%$ paraformaldehyde in cytoskeletal buffer 
(10 mM MES, $138 \mathrm{mM} \mathrm{KCl,} 3$ mM MgCl 2,4 mM EGTA, pH 6.1). Fixed cells were rinsed $3 \mathrm{x}$ in TBS for $5 \mathrm{~min}$ each and then blocked and permeabilized with $5 \%$ goat serum $/ 1 \%$ BSA/ $0.2 \%$ Triton-X for $1 \mathrm{hr}$ at room temperature. Cells were stained with one of the GSK3 primary antibodies diluted in $2 \%$ goat serum and incubated overnight at $4^{\circ} \mathrm{C}(12 \mathrm{~B} 2-1: 100 ; 15 \mathrm{C} 2-1: 100$; total GSK3 $\alpha / \beta-$ $1: 200)$. Cells were incubated in AlexaFluor goat anti-mouse IgG1 488 (A21121, Thermo) for 12B2 or 15C2 and AlexaFluor goat anti-rabbit 568 (A11036, Thermo) for total GSK3 $\beta / \alpha$ (all diluted $1: 500$ in $2 \%$ goat serum). DAPI counterstain $(0.5 \mu \mathrm{g} / \mathrm{ml}, \mathrm{D} 1306$, Thermo) was added to the first of four TBS rinses. Control stains were performed where the primary antibodies were omitted to confirm that each secondary label was specific to the appropriate primary antibody (Supplementary Figure S3A). Image z-stacks ( $0.5 \mu \mathrm{m}$ step size) were taken using a Nikon A1+ laser scanning confocal microscope system equipped with 488, 561, and 640 solid-state lasers, Nikon Elements AR software, and the images (maximum intensity projections) were prepared for publication using Adobe Photoshop and Illustrator.

\section{Tissue Immunohistochemistry}

Immunohistochemistry was performed on human control (temporal lobe) and rat tissue sections (40 $\mu \mathrm{m}$ thick) following established protocols (Kanaan et al., 2016). The tissue was incubated with purified GSK3 antibodies (12B2 - 1:500 or 15C2 - 1:1,000) overnight at $4^{\circ} \mathrm{C}$, followed by goat antimouse biotinylated secondary antibody at 1:500 (115-065166, Jackson Immuno Research) and then ABC Elite solution (according to the manufacturer's instructions; PK-6100, Vector Labs, Burlingame, CA, USA). The tissue was developed using $3,3^{\prime}$-diaminobenzidine (D5637, Sigma) at $0.5 \mathrm{mg} / \mathrm{ml}$ in TBSTx with $0.003 \% \mathrm{H}_{2} \mathrm{O}_{2}$ for $8 \mathrm{~min}$. Control sections that were stained following the same procedure, but without the primary antibodies were performed (Supplementary Figure S3B). Images were acquired as Z-stacks ( $0.9 \mu \mathrm{m}$ step size) with a Nikon Eclipse 90i microscope, a Nikon DS-Ril camera, and Nikon Elements AR software (Nikon Instruments Inc., Melville, NY, USA), and the images (displayed using the extended depth of focus function) were prepared for publication using Adobe Photoshop and Illustrator.

\section{GSK3 $\beta$ Kinase Activity Assays}

The GSK3 $\beta$ Kinase Enzyme System kit (V1991, Promega) was used to generate a standard curve of GSK3 $\beta$ activity per the manufacturer's instructions. The active GSK3 $\beta$ enzyme (G09-10G, lot P1578-8, Signal Chem) was brought to final concentrations of $12,9.6,7.2,4.8$, and $2.4 \mathrm{ng} / \mu \mathrm{l}$ in $25 \mu \mathrm{l}$ reaction mixture containing $100 \mu \mathrm{M}$ ATP (V915A, Promega) in reaction buffer (40 mM Tris- $\mathrm{HCl}, \mathrm{pH} 7.4,20 \mathrm{mM} \mathrm{MgCl}_{2}$ and $0.1 \mathrm{mg} / \mathrm{ml}$ bovine serum albumin; supplied as a $5 \mathrm{x}$ stock). The reactions were incubated at $30^{\circ} \mathrm{C}$ for $15 \mathrm{~min}$. The reactions were terminated and remaining ATP depleted by adding $25 \mu \mathrm{l}$ ADP-Glo ${ }^{\mathrm{TM}}$ reagent (V912A, Promega) made according to the manufacturer's instructions. After $40 \mathrm{~min}$ incubation at room temperature, $50 \mu \mathrm{l}$ of the kinase detection reagent (V913A and V914A, Promega, made according to manufacturer's instructions) was added to the reaction and incubated for $30 \mathrm{~min}$ at room temperature. All samples were run in triplicate. Then the luminescence was measured using a GloMax Muli-Detection plate reader (E7031, Promega). The relative luminescence units are directly proportional to the amount of ATP used during the kinase reaction.

\section{Nonphospho-S9 GSK3 $\beta$ Western Blotting Curve}

The $12 \mathrm{~B} 2$ and 15C2 GSK3 $\beta$ antibodies were tested using samples comprised of known amounts of npS9 GSK3 $\beta$ and pS9 GSK3 $\beta$. The npS9 GSK3 $\beta$ was obtained by incubating GSK3 $\beta$ ( $1 \mu \mathrm{g}$, Thermo, PV3365) with alkaline phosphatase (15 $\mathrm{U}$, Thermo, EF0654) for $5 \mathrm{~h}$ at $30^{\circ} \mathrm{C}$. The pS9 GSK3 $\beta$ was generated by incubating GSK3 $\beta$ ( $1 \mu \mathrm{g})$ with Akt1 (1 $\mu \mathrm{g}$, P2999, Thermo) and ATP (1 mM, N0440S, New England BioLabs) in kinase buffer $\left(20 \mathrm{mM}\right.$ Tris- $\mathrm{HCl}, \mathrm{pH} 7.5,10 \mathrm{mM} \mathrm{MgCl}_{2}$, $5 \mathrm{mM}$ DTT) for $5 \mathrm{~h}$ at $30^{\circ} \mathrm{C}$. Akt1 is a kinase known to phosphorylate S9 in GSK3 $\beta$ (Cross et al., 1994, 1995). The following seven samples were generated that matched the levels of npS9 GSK3 $\beta$ used in the kinase activity assay curve above: (1) $0 \%$ npS9 GSK3 $\beta$ (300 ng/lane pS9 GSK3 $\beta$ ), (2) 10\% npS9 GSK3 $\beta$ $(30 \mathrm{ng}+270 \mathrm{ng} / \mathrm{lane}),(3) 20 \%$ npS9 GSK3 $\beta$ (60 ng + $240 \mathrm{ng}$ pS9 GSK3 $\beta$ ), (4) 40\% npS9 GSK3 $\beta$ (120 ng + 180 ng pS9 GSK3 $\beta$ ), (5) $60 \%$ npS9 GSK3 $\beta$ (180 ng + 120 ng pS9 GSK3 $\beta$ ), (6) $80 \%$ npS9 GSK3 $\beta$ (240 ng + 60 ng pS9 GSK3 $\beta$ ), and (7) 100\% npS9 GSK3 $\beta$ $(300 \mathrm{ng}+0 \mathrm{ng}$ pS9 GSK3$\beta$ ). The samples were added to Laemmli sample buffer, loaded at a total of $300 \mathrm{ng} /$ lane, and separated on a 7.5\% TGX precast Criterion gel for SDS-PAGE and subsequently processed for western blotting using $12 \mathrm{~B} 2$ or $15 \mathrm{C} 2$ antibody and total GSK $3 \beta \alpha / \beta$ as described above.

\section{HEK293T Cell Culture Calyculin A Treatment}

HEK293T cells were grown for $48 \mathrm{hrs}$ and then treated with 10 nM calyculin A (9902S, Cell Signaling Technology, Beverly, MA, USA), a potent protein phosphatase inhibitor, for $30 \mathrm{~min}$ to induce phosphorylation of S9 GSK3 $\beta$ prior to being collected in lysis buffer (as above). Lysates were sonicated and centrifuged at $12,000 \times g$ for $10 \mathrm{~min}$, the supernatants were collected the Bradford Protein Assay was used to determine total protein concentrations before being used in sandwich ELISA and GSK3 $\beta$ activity assays.

The same lysates were used in a sandwich ELISA as described previously (Kanaan et al., 2016). Briefly, all of these assays were performed by coating wells in 96 well plates (Corning, \#3590) with 12B2 antibody (250 ng/well) as the capture antibody, wells were blocked with $5 \%$ non-fat dried milk $(1 \mathrm{~h})$, then incubated with the samples (see below), then incubated with rabbit anti-total GSK3 $\alpha / \beta$ antibody $(0.5 \mu \mathrm{g} / \mathrm{ml}, 1.5 \mathrm{~h}$, same antibody as above), and then incubated with goat anti-rabbit antibody conjugated to horseradish peroxidase (Vector Labs, PI1000; $(0.2 \mu \mathrm{g} / \mathrm{ml} ; 1.5 \mathrm{~h})$. Signal was detected with TMB for $25 \mathrm{~min}$ and then the reaction was stopped using 3.6\% $\mathrm{H}_{2} \mathrm{SO}_{4}$. The absorbance at $450 \mathrm{~nm}$ was measured and blank wells were used to obtain background absorbance, which was removed from sample signals. The following sandwich ELISAs sample sets were 
assayed. A recombinant npS9 GSK3 $\beta$ protein standard was run to determine the amount of bound npS9 GSK3 $\beta$ in the experimental lysate samples. Briefly, $2 \mu \mathrm{g}$ of recombinant GSK3 $\beta$ (G09-10G, Signal Chem) was incubated with $60 \mathrm{U}$ alkaline phosphatase (EF0651, Fermentas) at $30^{\circ} \mathrm{C}$ for $2 \mathrm{~h}$ to create the npS9 GSK3 $\beta$ protein standard. Then $300-0.29 \mathrm{ng} /$ well npS9 GSK3 $\beta$ was used to create the standard curve (triplicate samples per concentration). The absorbance values were $\log _{10}$ transformed and fit to a sigmoidal curve $\left(r^{2}=0.999\right)$ and this was used to interpolate the protein amounts in the experimental HEK cell lysate samples. A HEK293T lysate standard curve also was run to establish that the assay produces linear detection of npS9 GSK3 $\beta$ amounts from lysate samples. The HEK293T lysate samples were applied at 7.5, $15,30,60$, and $120 \mu \mathrm{g}$. Finally, HEK293T lysates from control and calyculin A treated cells were incubated in the sandwich ELISAs (60 $\mu \mathrm{g}$ protein). For these experimental samples, the absorbance values were used to interpolate unknown values of npS9 GSK3 $\beta$ levels from the recombinant GSK3 $\beta$ standard curve assay (from above) and the interpolated values were used for comparisons between untreated control cells and calyculin A treated cells.

The same lysates were also used to measure GSK3 $\beta$ kinase activity using an assay that combined the sandwich ELISA approach with the GSK3 $\beta$ kinase activity assay described above. Wells were coated with 12B2 (250 ng/well, diluted in borate saline), blocked and then the samples were applied. Three sample sets were tested, (1) a GSK3 $\beta$ enzyme standard (300 $9.4 \mathrm{ng}$, diluted in TBS, G09-10G, Signal Chem), (2) control HEK cell lysates and calyculin A (10 nM) treated HEK cell lysates, and (3) both HEK cell lysates with a TCS-2002 (100 $\mu \mathrm{M})$, a GSK3 $\beta$-specific inhibitor (Saitoh et al., 2009). The GSK3 $\beta$ standard was used to ensure the experimental sample signals were within the linear range of the assay. The control and calyculin A treated lysates were used to confirm whether the changes in npS9 GSK3 $\beta$ levels seen in western blotting and sandwich ELISAs were related to an actual reduction in GSK3 $\beta$ kinase activity. The TCS2002 inhibitor was used to confirm that the signals were derived from GSK $3 \beta$. After sample incubation, the wells were rinsed and incubated in $50 \mu \mathrm{l} /$ well GSK3 $\beta$ activity reaction buffer [100 $\mu \mathrm{M}$ ATP (V915A, Promega), 40 mM Tris- $\mathrm{HCl}, \mathrm{pH}$ 7.4, $20 \mathrm{mM} \mathrm{MgCl}_{2}$ and $0.1 \mathrm{mg} / \mathrm{ml}$ bovine serum albumin] for $1 \mathrm{~h}$ at $30^{\circ} \mathrm{C}$. Then, the kinase reaction was stopped with $50 \mu \mathrm{l} /$ well $^{\mathrm{ADP}-G \mathrm{o}^{\mathrm{TM}}}$ reagent (V912A, Promega) made according to the manufacturer's instructions. After $40 \mathrm{~min}$ incubation at room temperature, $100 \mu \mathrm{l}$ of the kinase detection reagent (V913A and V914A, Promega, made according to manufacturer's instructions) was added to the reaction and incubated for $30 \mathrm{~min}$ at room temperature. Then the luminescence was measured using a GloMax Muli-Detection plate reader. The relative luminescence units are directly proportional to the amount of ATP used during the kinase reaction.

\section{Akt Inhibitor and Protein Phosphatase Treatments in HEK293T Cell Cultures}

HEK293T cells were grown for $48 \mathrm{hrs}$ and then treated with either nothing (control), an Akt-specific inhibitor (AZD-5363, $1 \mu \mathrm{M}$, 15406, Cayman Chemical) (Davies et al., 2012; Li et al., 2013), a protein phosphatase inhibitor (calyculin A, $10 \mathrm{nM}, 9902 \mathrm{~S}$, Cell Signaling Technology) or both AZD-5363 and calyculin A. In the dual treatment cultures, cells were first treated with AZD-5363 for $1 \mathrm{~h}$ to inhibit the action of Akt on GSK3 (i.e., phosphorylation at S9/21), and then calyculin A was applied for $30 \mathrm{~min}$ to establish whether protein phosphatases dephosphorylate S9/21 independent of the Akt pathway (protein phosphatases can increase Akt activity via causing accumulation of phospho-Akt or they can directly dephosphorylate GSK3). Lysates were sonicated and centrifuged at $12,000 \times g$ for $10 \mathrm{~min}$, the supernatants were collected for western blotting analysis as above. The Bradford Protein Assay was used to determine total protein concentrations.

\section{Statistics and Data Analysis}

All curve fitting and statistical analyses were performed using Prism 6.0 (GraphPad Software, Inc.). The sandwich ELISA data from the treatment of HEK293T cells with calyculin A were compared using unpaired $t$-test. The western blotting Akt inhibitor and protein phosphatase inhibitor experiment data were compared using a one-way ANOVA, and post hoc comparisons were made using the Holm-Sidak test. Immunoblotting signal for $12 \mathrm{~B} 2$ and $15 \mathrm{C} 2$ were correlated to GSK3 $\beta$ enzyme activity using a Pearson's $r$ correlation analysis. The GSK3 $\beta$ kinase activity assay data were compared using a twoway ANOVA with calyculin treatment and TCS-2002 treatment as the two factors, and post hoc comparisons were made using the Holm-Sidak test. All tests were two-tailed and significance set at $p<0.05$.

\section{RESULTS}

\section{Immunization with npS9 GKS3 $\beta$ Peptides}

Mouse N00 was immunized with the N-terminal KLH npS9 GSK3 $\beta$ peptide and animals T10 and E10 were immunized with a mixture of 3 peptides ( $\mathrm{N}$-term $\mathrm{KLH}$, arginine enantiomer and the tandem npS9 GSK3 $\beta$ peptides). All of the animals exhibited strong titers against npS9 GSK3 $\beta$ and no detection of the pS9 GSK3 $\beta$ peptide (Supplementary Figures S1A,B). Animal T10 had the highest antibody titer after the third immunization boost $\left(\mathrm{A}_{450}=0.061\right.$ at 1:25,600; Supplementary Figure S1A) and was used for the first fusion. Animal N00 had the highest titer after the 6th immunization boost $\left(\mathrm{A}_{450}=0.374\right.$ at $1: 25,600$; Supplementary Figure S1B) and was used for a second fusion. Hybridoma fusion cultures were screened for reactivity with the npS9 GSK3 $\beta$, pS9 GSK3 $\beta$ and npS21 GSK3 $\alpha$ peptides to determine their specificity prior to subcloning (Supplementary Figures S1C,D). The 12B2 cultures showed stronger reactivity for $n p S 9$ GSK3 $\beta$ over npS21 GSK3 $\alpha$, and did not react with pS9 GSK3 $\beta$. The 15C2 culture showed slightly stronger reactivity with npS21 GSK3 $\alpha$ over npS9 GSK3 $\beta$, and did not react with pS9 GSK3 $\beta$. These cultures were subcloned three times, and with each subcloning step the clones with the strongest reactivity were continued forward (screened against the above peptides in indirect ELISAs) and selected for production and purification. Here, we characterized clone 12B2 (npS9 $\beta$-specific) and clone 
A

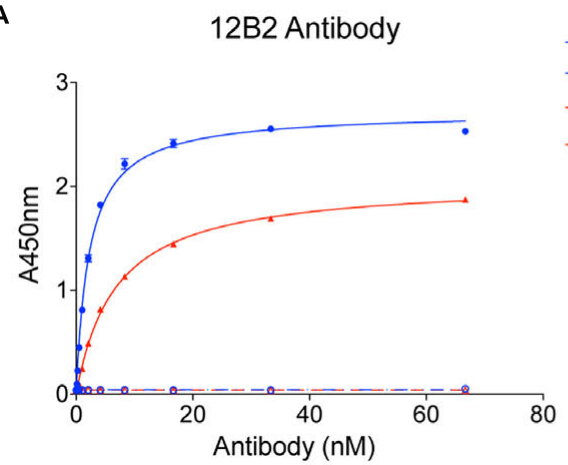

C

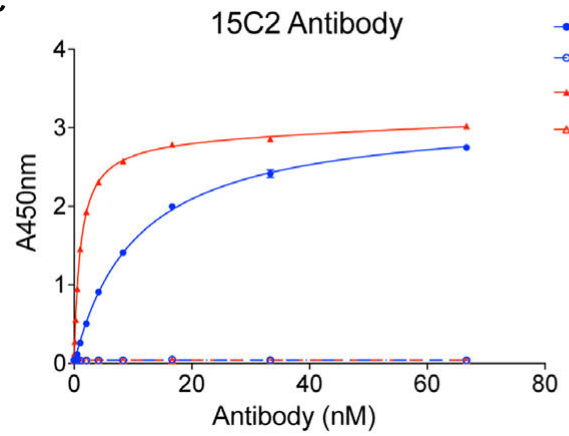

B

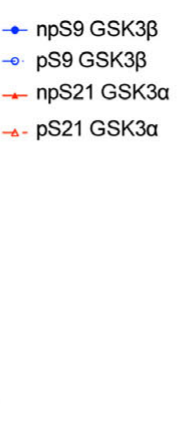

- npS9 GSK3ß

$\rightarrow$ pS9 GSK3 $\beta$

- npS21 GSK3a

$\Rightarrow-$ pS21 GSK3a

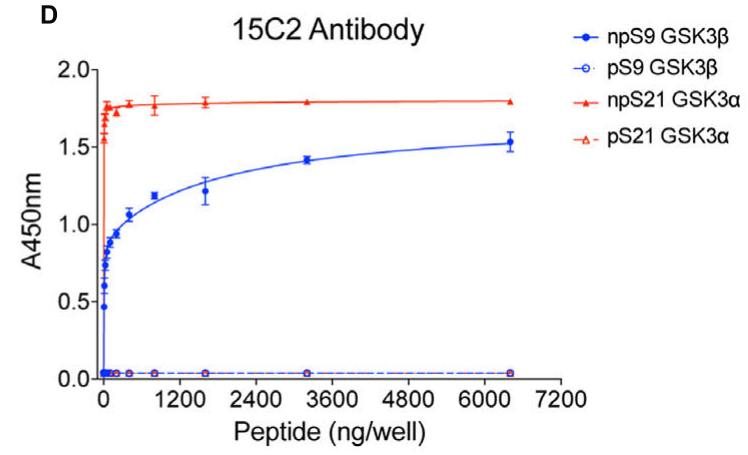

FIGURE 1 | $12 B 2$ and 15C2 are specific for nonphospho-Ser GSK3 $\beta / \alpha$ peptides. Each antibody was screened in indirect ELISA titers against npS9 GSK3 $\beta$, pS9 GSK3 $\beta, n p S 21$ GSK3 $\alpha$ and pS21 GSK3 $\alpha$ peptides ( $n=3$ independent experiments). (A) $12 B 2$ showed strong reactivity for npS9 GSK3 $\beta$ compared to npS21 GSK3 $\alpha$ peptides and did not react with pS9 or pS21 GSK3 peptides ( EC $_{50}$ values: $\mathrm{npS9}=2.1 \mathrm{nM}$; pS9 = indeterminate (id); $\mathrm{npS21}=6.4 \mathrm{nM}$; pS21 = id). (B) To further confirm the specificity of 12B2, ELISAs were performed by coating wells with a wide range of peptide amounts $(0-6.4 \mu \mathrm{g}$ peptide/well). $12 \mathrm{~B} 2$ showed strong reactivity with the npS GSK3 peptides $(\beta>\alpha)$, but did not react with pS GSK3 peptides. (C) $15 \mathrm{C} 2$ showed stronger reactivity for npS21 GSK3 $\alpha$ compared to npS9 GSK3 $\beta$ and did not react with pS9 or pS21 GSK3 peptides ( $E_{50}$ values: npS9 = 2.4 nM; pS9 = id; npS21 = 277 pM; pS21 = id). (D) To further confirm the specificity of $15 \mathrm{C} 2$, ELISAs were performed by coating wells with a wide range of peptide amounts $(0-6.4 \mu \mathrm{g}$ peptide/well). $15 \mathrm{C} 2$ showed strong reactivity with the npS GSK3 peptides, but did not react with pS GSK peptides. It is noteworthy that synthetic peptides provide a homogeneous source of modified peptides, and thus, are ideal for challenging the specificity of the antibodies against nonphospho-Ser and phospho-Ser residues in GSK3.

15C2 (npS $\beta / \alpha$-specific), both of which produce IgG1 isotype antibodies.

\section{B2 and 15C2 Antibody Specificity}

Once purified, we titered the antibodies using npS9 GSK3 $\beta$, pS9 GSK3 $\beta, n p S 21$ GSK $3 \alpha$ and $\mathrm{pS} 21$ GSK3 $\alpha$ peptides in indirect ELISAs. Clone 12B2 showed a higher affinity for npS9 GSK3 $\beta$ (2.3 nM) compared to $\mathrm{npS} 21 \mathrm{GSK} 3 \alpha$ (6.8 nM; Figure 1A). Clone 15C2 had higher affinity for npS21 GSK3 $\alpha$ (1.2 pM) compared to npS9 GSK3 $\beta$ (10.6 nM; Figure 1C). Neither of the antibodies reacted with pS9 GSK3 $\beta$ or pS21 GSK3 $\alpha$ peptides above background levels demonstrating their specificity for npS GSK3 across a broad range of antibody dilutions (starting as high as $67 \mathrm{nM}$ or 1:100 dilution; Figures 1A,C). Next, we further tested the limitations of $12 \mathrm{~B} 2$ and $15 \mathrm{C} 2$ specificity across a broad range of peptide concentrations ( 0 $6.4 \mu \mathrm{g} /$ well). There was strong reactivity with the npS peptides, but again, no signals above background for the phospho-Ser peptides confirming the specificity even at excessively high levels of purified synthetic phospho-Ser peptides (i.e., $6.4 \mu \mathrm{g} / \mathrm{well}$; Figures 1B,D). It is noteworthy, that synthetic peptides provide the most homogenous source of either phosphorylated or nonphosphorylated antigens. To confirm that the synthetic pS9 GSK3 $\beta$ peptide contained a phosphorylated-Ser residue we also performed an ELISA using the pS GSK3 $\beta$-specific antibody, and as expected, there was a strong signal demonstrating the peptide contained phosphoS9 residues (Supplementary Figure S1E).

Three recombinant GSK3 $\beta$ (his-tagged) and GSK3 $\alpha$ (GSTtagged) protein samples were generated: (1) GSK3 $\beta$ or $\alpha$ alone, (2) GSK3s incubated with alkaline phosphatase to dephosphorylate S9 in GSK3 $\beta$ or S21 in GSK3 $\alpha$, or (3) GSK3s incubated with Akt1 to phosphorylate S9 in GSK3 $\beta$ or S21 in GSK3 $\alpha$. These samples were used to establish the specificity of the $12 \mathrm{~B} 2$ and 15C2 with full-length GSK3 proteins. Blots were probed with each antibody and a rabbit anti-total GSK3 $\alpha / \beta$ antibody (Figures 2A,B), or a rabbit anti-pS9 GSK3 $\beta$ antibody and a mouse anti-total GSK3 $\beta$ antibody (Figure 2C). The 12B2 antibody showed strong specificity for npS9 GSK3 $\beta$ and did not react with pS9 GSK3 $\beta$, npS21 GSK $\alpha$ or pS21 GSK3 $\alpha$ proteins (Figure 2D). The 15C2 antibody showed a weak preference for npS9 GSK3 $\beta$ over npS21 GSK3 $\alpha$ and did not react with pS9 GSK3 $\beta$ or pS21 GSK3 $\alpha$ (Figure 2E). Phosphorylation of S9/S21 was confirmed using the pS9 GSK3 $\beta$ antibody (Figure 2F). 
A

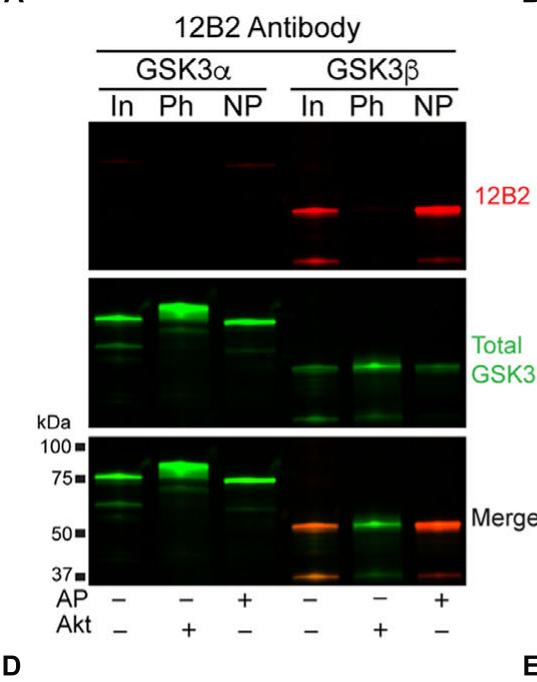

B

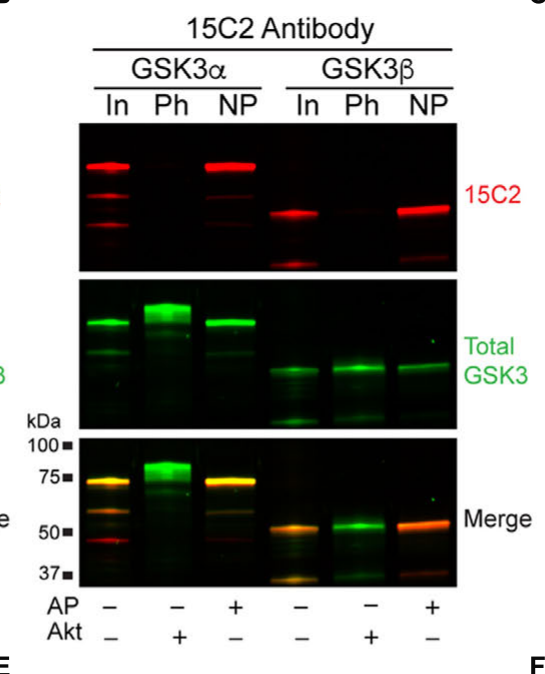

C

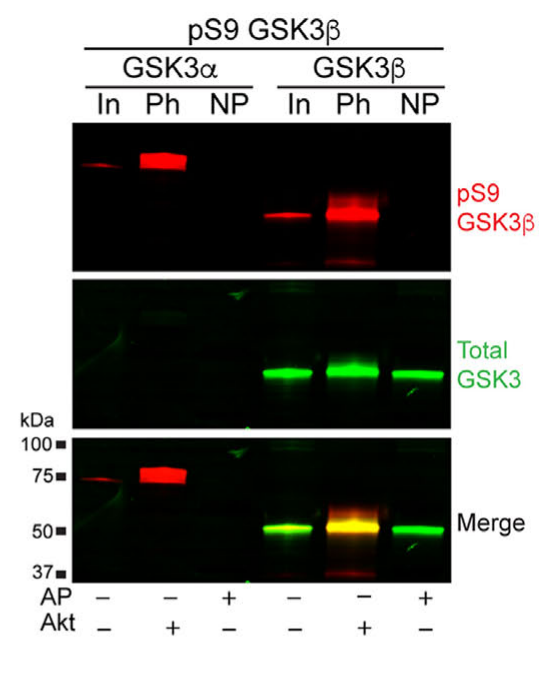

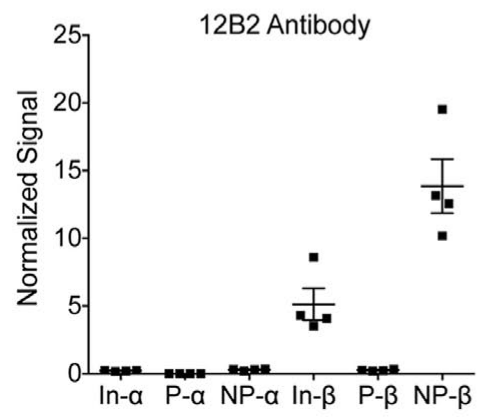

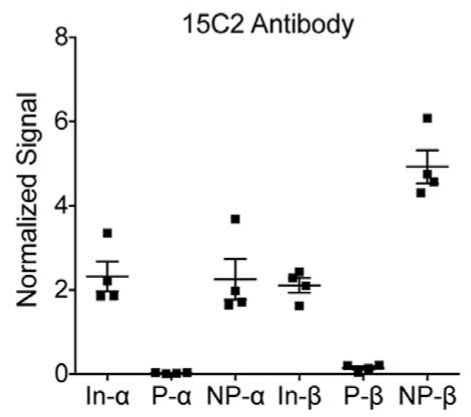

FIGURE 2 | 12B2 is specific for nonphospho-S9 recombinant GSK3 $\beta$, and $15 \mathrm{C} 2$ is specific for nonphospho-S9/21 recombinant GSK3 $\beta / \alpha$. (A-C) Western blots of recombinant GSK3 $\beta$ and $\alpha$ alone (input, In), phosphorylated S9 GSK3 $\beta$ and S21 GSK3 $\alpha$ proteins (Ph; i.e., Akt1 treated) and dephosphorylated S9 GSK3 $\beta$ and S21 GSK3 $\alpha$ proteins (NP; i.e., alkaline phosphatase treated). The GSK3 $\alpha$ is GST-tagged and GSK3 $\beta$ is his-tagged, and in each blot the 12B2 (A), 15 C2 (B) or pS9 GSK3 $\beta$ (C) antibodies are red, while total GSK3 $\alpha / \beta$ antibody is green. (D) Quantitation of the $12 B 2$ blots shows strong reactivity with npS9 GSK3 $\beta$, and none with npS21 GSK3 $\alpha$, pS9 GSK3 $\beta$ or pS21 GSK3 $\alpha$. (E) Quantitation of the $15 \mathrm{C} 2$ blots shows strong reactivity with npS9 GSK3 $\beta$ and npS21 GSK3 $\alpha$, but none with pS9 GSK3 $\beta$ or pS21 GSK3 $\alpha$. (F) Quantitation of the pS9 GSK3 blots confirm that the Akt1 treatment produced robust phosphorylation of S9 in GSK3 $\beta$ (and S21 in $\alpha$ ) and that the alkaline phosphatase treatment removed phosphorylation of S9 in GSK3 $\beta$ (and S21 in $\alpha$ ). Each experiment was repeated three-four independent times and all samples were loaded at $50 \mathrm{ng}$ GSK3/lane. The data are normalized to total GSK3 signal.

Next, we assessed the specificity and species cross reactivity of $12 \mathrm{~B} 2$ and $15 \mathrm{C} 2$ using human, mouse and rat brain lysates since GSK $3 \beta$ is $100 \%$ conserved and there is a notable similarity in GSK $3 \alpha$ (Figure 3A). Total GSK $3 \alpha / \beta$ antibody detected both forms in humans, mice and rats (Figures 3B,C). The $12 \mathrm{~B} 2$ antibody was specific for npS9 GSK3 $\beta$ and did not react with npS21 GSK3 $\alpha$ protein in human, mouse and rat lysates (Figure 3B). In contrast, 15C2 detected both npS GSK3 isoforms in human, mouse and rat lysates (Figure 3C). Cell lysates from HEK293T (human), SH-SY5Y neuroblastoma cells (human), U373 glioblastoma cells (human), primary neurons (rat), and Neuro-2a neuroblastoma cells (mouse) were used to validate the utility of $12 \mathrm{~B} 2$ and $15 \mathrm{C} 2$ across multiple cell types. In all cell types, 12B2 specifically labeled npS9 GSK3 $\beta$ (Supplementary Figure S2A) and $15 \mathrm{C} 2$ labeled both $n p S 21$ GSK3 $\alpha$ and npS9 GSK3 $\beta$ (Supplementary Figure S2B), but there were varying degrees of each isoform in the different cell types. We also used HEK293T cell lysates to establish the effectiveness of $12 \mathrm{~B} 2$ and $15 \mathrm{C} 2$ in lysate immunoprecipitations. The 12B2 antibody effectively immunoprecipitated GSK3 $\beta$ only (Figure $3 \mathrm{D}$ ), while the $15 \mathrm{C} 2$ antibody pulled down both GSK3 $\alpha$ and $\beta$ (Figure 3E). The non-immune mouse IgG control did not immunoprecipitate GSK $3 \alpha$ or $\beta$ (Figure 3 F).

Based on the collective results from the assays above, 12B2 is a npS9 GSK3 $\beta$-specific antibody and $15 \mathrm{C} 2$ is a $n p S 9 / 21$ GSK3 $\beta / \alpha$-specific antibody. Next, we further characterized their reactivity in cell and tissue immunostaining procedures. In general, immunofluorescence for $12 \mathrm{~B} 2$ produced stronger staining compared to $15 \mathrm{C} 2$ (Figure 4). The pattern of staining produced by $12 \mathrm{~B} 2$ was mostly punctate, and this was consistent in HEK cells (Figure 4A), SH-SY5Y cells (Figure 4C) and E18 rat cortical neurons (Figure 4E). The 15C2 antibody produced similar patterns of staining, but the overall signal was not as robust as 12B2 in HEK cells (Figure 4B), SH-SY5Y cells 
A

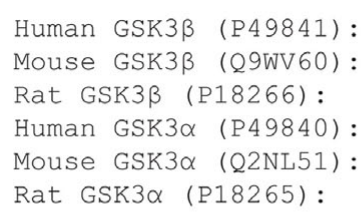

B

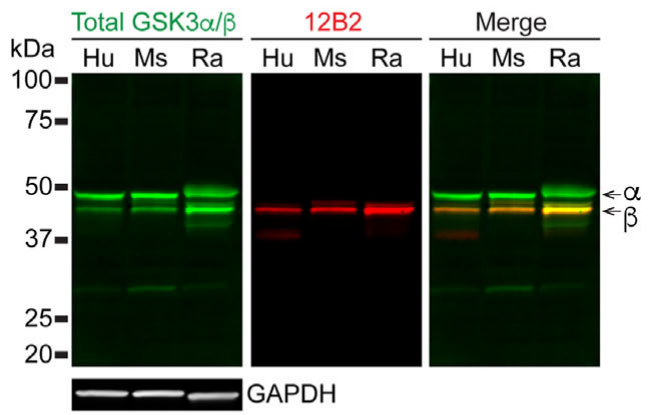

D

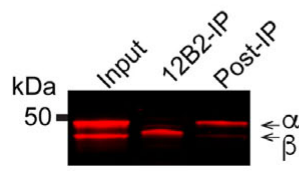

$E$

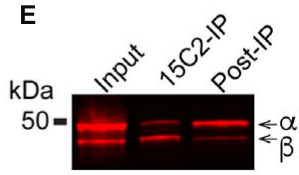

1 MSGRPRTTS SAESCKPVQQPSAFGS 25

MSGRPRTT'S'EAESCKPVQQPSAFGS 25

MSGRPRTT'SAESCKPVQQPSAFGS 25

GSGRARTSSFAEPGGGGGGGGPG 37

GSGRARTS'S'PAEPGGGGGGGGGGPG 37

GSGRARTS'S'

C
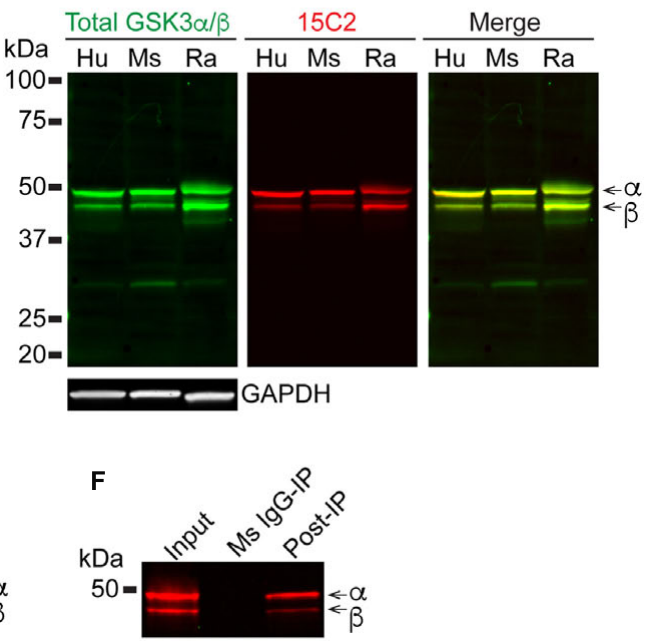

FIGURE 3 | 12B2 and 15C2 are specific for nonphospho-S GSK3 in brain lysates of human, mouse, and rat, and both effectively immunoprecipitate GSK3 from cell lysates. (A) Protein sequence alignments for GSK3 $\beta$ (amino acids 1-25) and GSK3 $\alpha$ (amino acids 13-37) from human, mouse and rat (Uniprot IDs in parentheses). (B,C) Blots of lysates from human, mouse and rat cortical tissue and GAPDH was used as a loading control (40 $\mu \mathrm{g} / \mathrm{lane}$ total protein loaded; experiment repeated three times). (B) 12B2 (red) specifically labeled GSK3 $\beta$, not GSK3 $\alpha$, in lysates and total GSK3 $/ \beta$ (green) was used to identify both isoforms. (C) $15 \mathrm{C} 2$ (red) labeled both GSK3 $\beta$ and GSK3 $\alpha$ in lysates and total GSK3 $/ \beta$ (green) was used to identify both isoforms. (D-F) The 12B2 (D), 15C2 (E), or control mouse $\lg G(\mathbf{F}$, Ms lgG) were used to immunoprecipitate GSK3 enzymes from HEK293T cell lysates. The starting lysate (Input) was incubated with magnetic beads coated with 12B2 (D), 15C2 (E), or Ms IgG control (F) antibodies. 12B2 pulled down only GSK3 $\beta$ (12B2-IP), 15C2 pulled down both GSK3 $\alpha$ and $\beta$ (15C2-IP) and Ms IgG did not pull down GSK3 $\alpha$ or $\beta$ (MslgG-IP). The post-IP lysates were also run for comparisons to the input samples. These experiments were performed three independent times.

(Figure 4D) and primary neurons (Figure 4F). Primary delete stains confirmed that the pattern of staining was dependent upon the 12B2 and 15C2 antibodies (Supplementary Figure S3A).

Brain tissue sections from rat and human brains were processed for IHC. Both 12B2 (Figure 4G) and 15C2 (Figure 4H) produced reactivity in the somata and processes of neurons, as well as the parenchyma in the rat (retrosplenial cortex depicted) and human brain (temporal lobe depicted). Primary delete sections confirmed the signal was due to the primary antibodies, and not non-specific reactivity from other components of the staining procedure (Supplementary Figure S3B).

Finally, HEK293T cells were treated with siRNAs to further confirm the specificity of $12 \mathrm{~B} 2$ and $15 \mathrm{C} 2$ antibodies. Treatment of cells with GSK3 $\beta$ siRNA reduced 12B2 signal $(-50 \%)$ in the GSK3 $\beta$ band, while GSK3 $\alpha$ siRNA caused an increase in $12 \mathrm{~B} 2$ signal $(+35 \%)$ in the GSK3 $\beta$ band compared to control (Figures 5A,B). Quantitation of total GSK3 $\alpha / \beta$ antibody signal showed that GSK3 $\alpha$ siRNA reduced GSK3 $\alpha$ levels (-66\%) and increased GSK3 $\beta$ ( $+29 \%)$, while GSK3 $\beta$ siRNA reduced GSK3 $\beta(-41 \%)$ and increased GSK3 $\alpha(+17 \%)$ when compared to control cells (Figure 5C). The reduction in $12 \mathrm{~B} 2$ signal with GSK3 $\beta$ siRNA was apparent in the reduced signal with immunocytochemistry (Figure 5D). Treatment of cells with
GSK3 $\alpha$ siRNA reduced only the $\alpha$ band (-84\%) detected by $15 \mathrm{C} 2$, and treatment with GSK $3 \beta$ siRNA reduced only the $\beta$ band $(-49 \%)$ detected by $15 \mathrm{C} 2$ compared to control (Figures 6A,B). With GSK $3 \alpha$ siRNA the GSK3 $\beta$ band detected by $15 \mathrm{C} 2$ was increased $(+22 \%)$, and with GSK3 $\beta$ siRNA the GSK $3 \alpha$ band detected by $15 \mathrm{C} 2$ was increased $(+18 \%)$ compared to control. Quantitation of total GSK $3 \alpha / \beta$ antibody signal showed that GSK3 $\alpha$ siRNA reduced GSK3 $\alpha$ levels (-66\%) and increased GSK3 $\beta(+24 \%)$, while GSK3 $\beta$ siRNA reduced GSK3 $\beta(-40 \%)$ and increased GSK $3 \alpha(+9 \%)$ when compared to control cells (Figure 6C). The reduction in GSK $3 \alpha$ and GSK3 $\beta$ staining with $15 \mathrm{C} 2$ was apparent in the reduced signals with immunocytochemistry (Figure 6D). The level of GAPDH knockdown was $-82 \%$ (Supplementary Figure S4A), and GSK $3 \alpha$ and GSK $3 \beta$ levels were reduced minimally by $\sim 17 \%$ with GAPDH siRNA treatment (Supplementary Figure S4B).

\section{GSK3 $\beta$ Antibody Reactivity Correlates with GSK3 $\beta$ Enzyme Activity}

We used recombinant GSK3 $\beta$ proteins for our initial demonstration that $12 \mathrm{~B} 2$ and $15 \mathrm{C} 2$ reactivity reflects GSK3 $\beta$ enzyme activity (Figures 7A-E). First, the level of GSK3 $\beta$ activity 


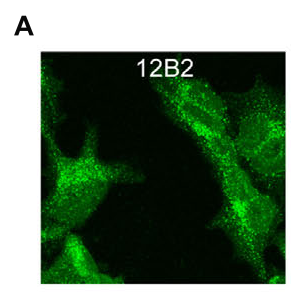

C

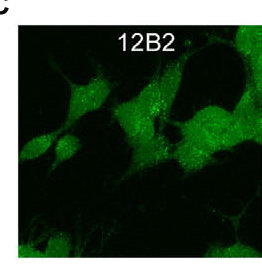

E

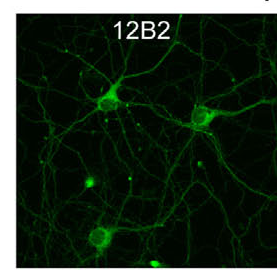

$\mathbf{F}$

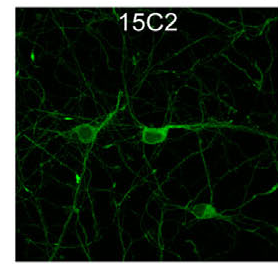

HEK293T Cells

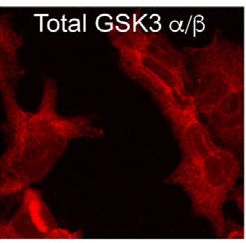

SH-SY5Y Cells

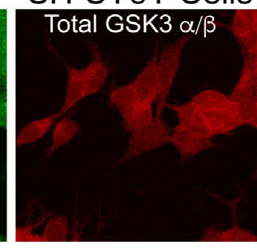

Primary Rat Neurons
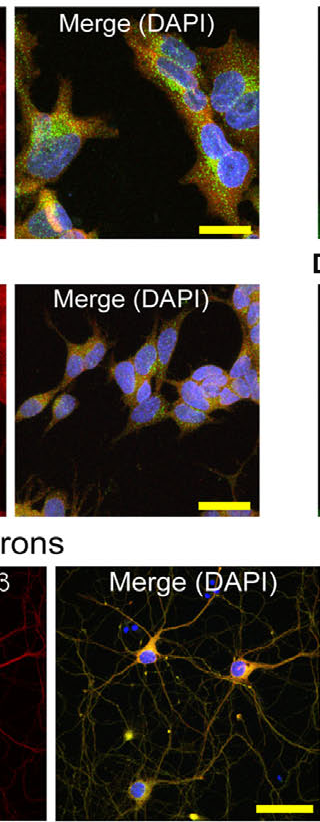

Primary Rat Neurons
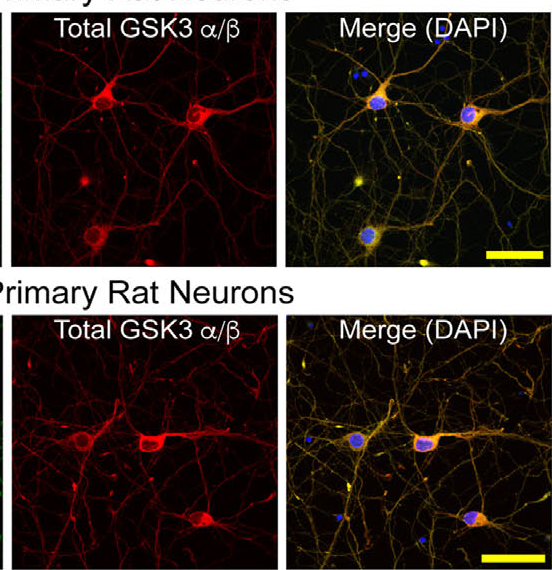

B

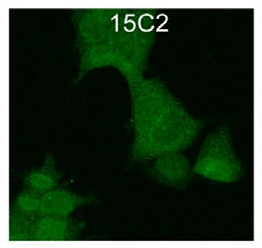

D

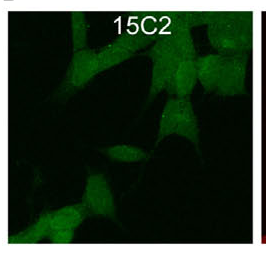

G

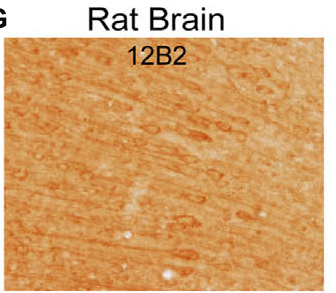

H

Rat Brain

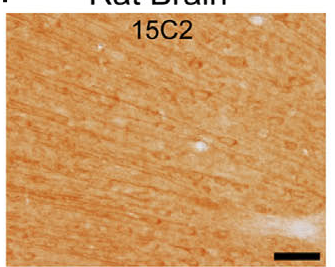

HEK293T Cells

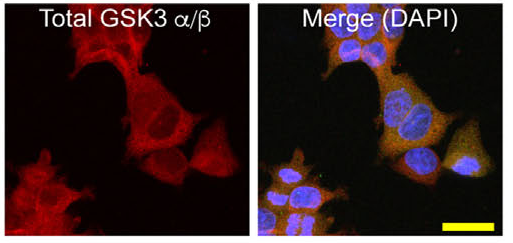

SH-SY5Y Cells

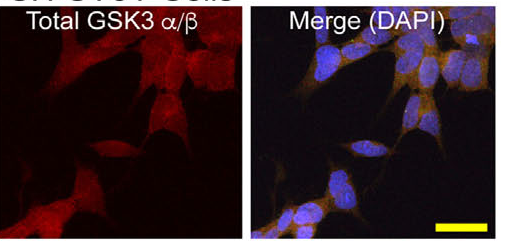

Human Brain

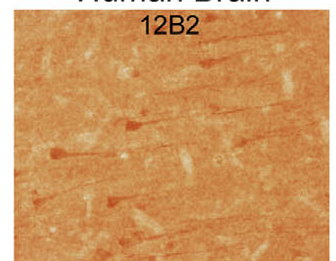

Human Brain

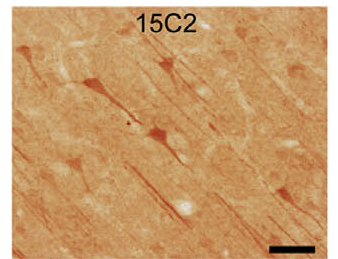

FIGURE 4 | GSK3 $\beta$ antibody immunostaining in cultured cells and tissue sections. (A,B) HEK293T cells stained with 12B2 (A, green) and 15C2 (B, green). (C,D) Undifferentiated SH-SY5Y cells stained with 12B2 (C, green) and $15 \mathrm{C} 2$ (D, green). (E,F) Rat primary cortical neurons (E18) stained with 12B2 (E, green) and $15 \mathrm{C} 2$ (F, green). In A-F, all cells were also stained with total GSK3 $\alpha / \beta$ (red) and DAPI (blue in merged image). The pattern of staining with $12 \mathrm{~B} 2$ and $15 \mathrm{C} 2$ was punctate staining throughout the cells, and 12B2 produced stronger signal than 15C2 in each cell type. Scale bars $=25 \mu \mathrm{m}$. (G,H) Brain sections in rat (left, retrosplenial cortex displayed) and human (right, temporal cortex) stained with 12B2 (G) or 15C2 (H). In general, both antibodies produced clear somatodendritic and parenchymal staining in human and rat brain sections. Scale bars $=50 \mu \mathrm{m}$.

was assessed using an in vitro GSK3 $\beta$ kinase activity assay that uses luminescence to detect the amount of ADP (i.e., ATP used) in a reaction mixture. The assay showed a positive linear dose-response $\left(r^{2}=0.93\right.$, slope $\left.=15727 \pm 1080, p<0.0001\right)$ with increasing npS9 GSK3 $\beta$ (30 - 300 ng) (Figure 7A). Next, we phosphorylated S9 by incubating GSK3 $\beta$ with Akt1 or dephosphorylated S9 by incubating GSK3 $\beta$ with phosphatase and then brought all samples to the same amount of total GSK3 $\beta$ in each lane (300 ng total/lane containing $0,10,20,40,60,80$, or $100 \%$ npS9 GSK $3 \beta$ ). Blots probed with $12 \mathrm{~B} 2$ (Figures $7 \mathbf{B}, \mathbf{C}$ ) and 15C2 (Figures 7D,E) showed positive linear reactivity (12B2: $r^{2}=0.92$, slope $=0.0102 \pm 0.0006, p<0.0001 ; 15 C 2: r^{2}=0.90$, slope $=0.001478 \pm 0.0001, p<0.0001)$ with increasing npS9 GSK $3 \beta$. Notably, $12 \mathrm{~B} 2$ and $15 \mathrm{C} 2$ did not show reactivity in the 0\% npS9 GSK3 $\beta$ (containing 300 ng phospho-S9 GSK3 $\beta$ ) samples confirming the specificity for nonphospho-S9 GSK3 protein. Finally, we correlated 12B2 or 15C2 blotting signal with GSK3 $\beta$ kinase activity levels. Both 12B2 $(r=0.99, p=0.0002)$ and $15 \mathrm{C} 2$ $(r=0.99 ; p<0.0001)$ showed a strong positive correlation with
GSK3 $\beta$ activity assay as determined by the luminescence activity assay.

\section{Protein Phosphatase Inhibition Decreases npS9 GSK3 $\beta$ Levels and GSK3 $\beta$ Enzyme Activity in Cells}

To provide a proof-of-principle demonstration of how these new reagents can be used to gain biological insights we focused on the 12B2 antibody because of its specificity for the GSK3 $\beta$ isoform. We used 12B2 to examine the regulation of GSK3 $\beta$ by protein phosphatases in cells. We treated HEK cells for $30 \mathrm{~min}$ with $10 \mathrm{nM}$ calyculin $\mathrm{A}$, a potent protein phosphatase inhibitor (Ishihara et al., 1989; Resjo et al., 1999), which increases S9 phosphorylation in GSK3 $\beta$ (Morfini et al., 2004; Kim et al., 2009; Xiao et al., 2010). The cell lysates were analyzed in sandwich ELISAs, GSK3 $\beta$ kinase activity assays, immunofluorescence, and western blot. 

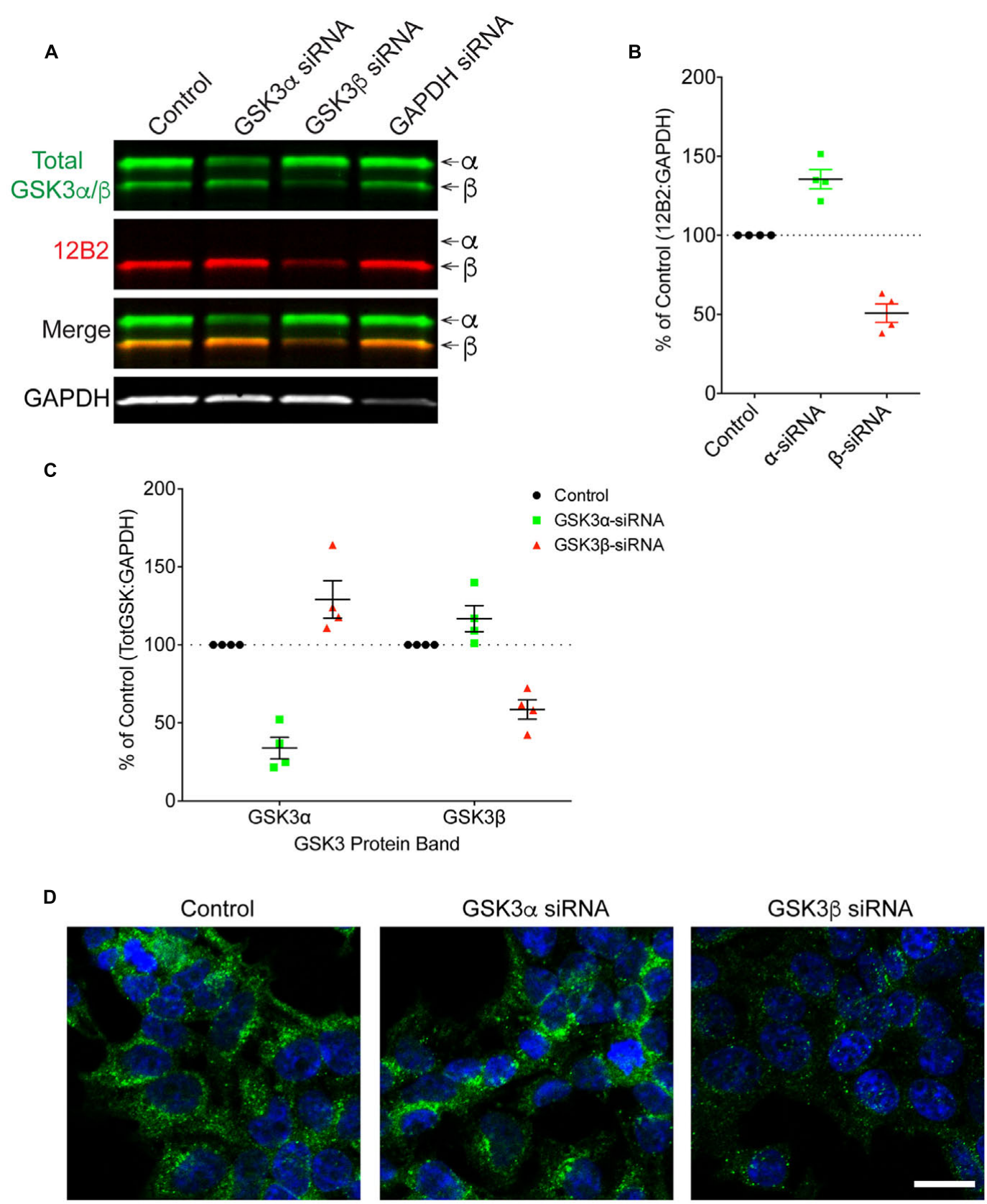

FIGURE 5 | siRNA knockdown of GSK3 $\alpha$ and GSK3 $\beta$ demonstrate specificity of the $12 B 2$ antibody. (A) HEK293T cells were treated with control, GSK3 $\alpha$, GSK3 $\beta$ or GAPDH siRNAs and probed with 12B2 (red) and total GSK3 $3 / \alpha$ (green) antibodies. (B) Quantitation of $12 B 2$ signal shows that GSK3 $\beta$ siRNA caused a reduction of 50\% for GSK3 $\beta$ when compared to control cells, while GSK3 $\alpha$ siRNA caused an increase in GSK3 $\beta$ (+35\%). (C) Quantitation of total GSK3 $\alpha / \beta$ antibody signal shows that GSK3 $\alpha$ siRNA caused a loss of $66 \%$ for GSK3 $\alpha$ and an increase in GSK3 $\beta$ ( $+29 \%)$ when compared to controls. Quantitation of total GSK3 $\alpha / \beta$ antibody signal shows that GSK3 $\beta$ siRNA caused a loss of $41 \%$ for GSK3 $\beta$ and an increase in the GSK3 $\alpha(+17 \%)$ when compared to control cells. All immunoblotting data are normalized to GAPDH signal and expressed as percent of the control group to illustrate the siRNA-mediated changes in signal.

(D) Immunocytofluorescence of HEK293T cells confirms the reduction in 12B2 detection of npS9 GSK3 $\beta$, which produces a punctate staining pattern, in GSK3 $\beta$ siRNA treated cells compared to control and GSK3 $\alpha$ siRNA treated cells. Scale bars $=20 \mu \mathrm{m}$. Four independent experiments were performed. GAPDH siRNA quantitation is provided in Supplementary Figure S4.

First, we used $12 \mathrm{~B} 2$ sandwich ELISAs to quantitatively measure the amount of npS9 GSK3 $\beta$ in these lysate samples. A recombinant npS9 GSK3 $\beta$ standard curve $\left(r^{2}=0.999\right)$ was used to interpolate the amount of npS9 GSK3 $\beta$ bound from the lysates (Figure 8A). The 12B2 sandwich ELISAs were confirmed to linearly detect npS9 GSK3 $\beta$ in HEK cell lysates by applying 120 , $60,30,15$, and $7.5 \mu \mathrm{g}$ of total lysate protein, which produced a linear response curve $\left(r^{2}=0.988\right)$ and $7.4,5.2,3.5,2.0$, and $0.9 \mathrm{ng}$ 

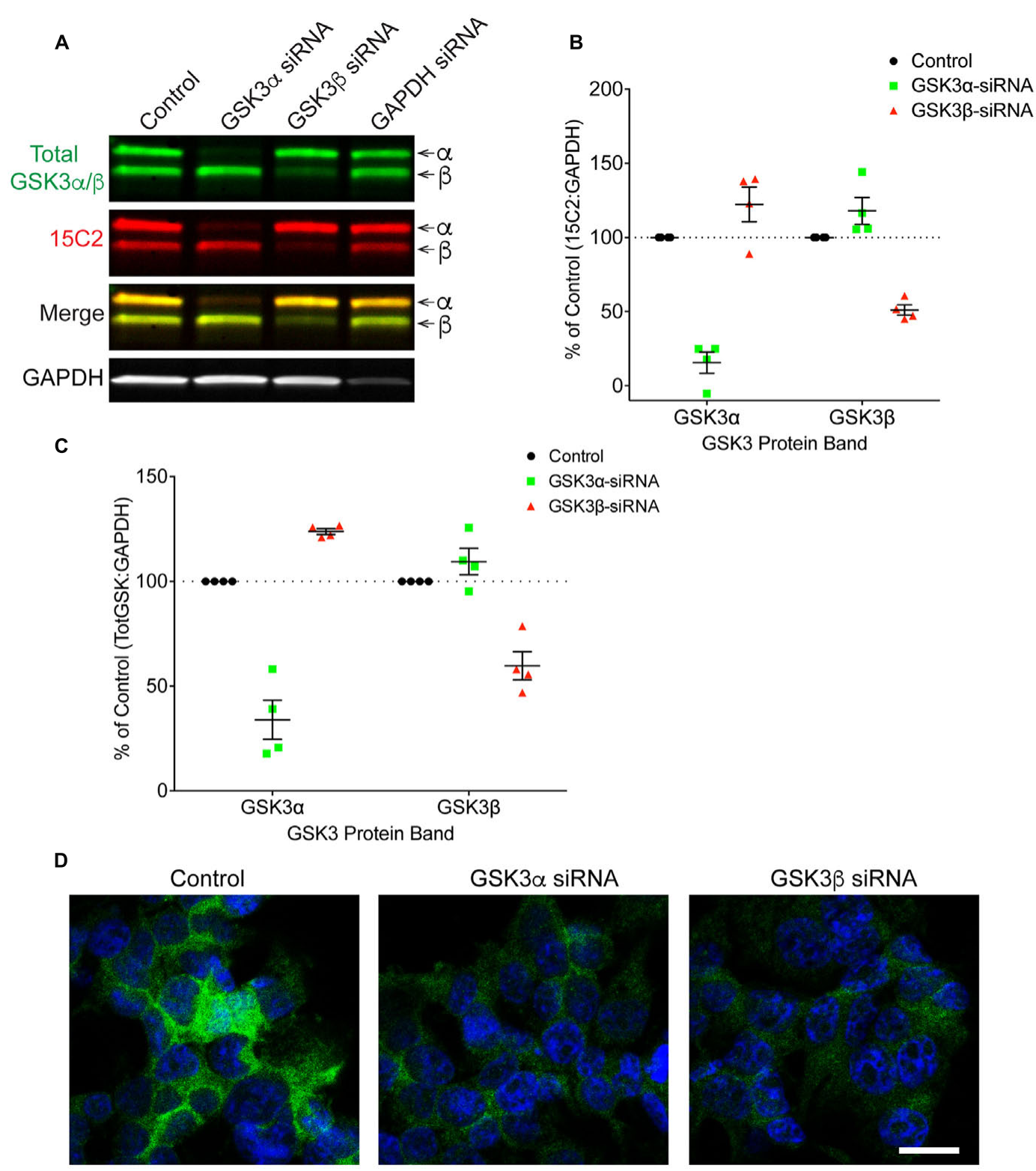

FIGURE 6 | siRNA knockdown of GSK3 $\alpha$ and GSK3 $\beta$ demonstrate specificity of the $\mathbf{1 5 C 2}$ antibody. (A) HEK293T cells were treated with control, GSK3 $\alpha$, GSK3 $\beta$ or GAPDH siRNAs and probed with $15 \mathrm{C} 2$ (red) and total GSK3 $\beta / \alpha$ (green) antibodies. (B) Quantitation of 15C2 signal shows that GSK3 $\alpha$ siRNA caused a loss of $84 \%$ for GSK3 $\alpha$ and an increase in GSK3 $\beta$ (+22\%) when compared to control cells. Quantitation of $15 \mathrm{C} 2$ shows that GSK3 $\beta$ siRNA caused a loss of $49 \%$ for GSK3 $\beta$ and an increase in GSK3 $\alpha(+18 \%)$ when compared to control. (C) Quantitation of total GSK3 $\alpha / \beta$ antibody signal shows that GSK3 $\alpha$ siRNA caused a loss of $66 \%$ in GSK3 $\alpha$ and an increase in GSK3 $\beta$ ( $+24 \%$ ) when compared to controls. Quantitation of total GSK3 $\alpha / \beta$ antibody signal shows that GSK3 $\beta$ siRNA caused a loss of $40 \%$ for the GSK3 $\beta$ and an increase in GSK3 $\alpha$ (+9\%) when compared to control cells. All immunoblotting data are normalized to GAPDH signal and expressed as percent of the control group to illustrate the siRNA-mediated changes in signal. (D) Immunocytofluorescence of HEK293T cells confirms the reduction in $15 \mathrm{C} 2$ detection of npS21 GSK3 $\alpha$ or npS9 GSK3 $\beta$ when treated with GSK3 $\alpha$ siRNA or GSK3 $\beta$ siRNA, respectively. Scale bars $=20 \mu \mathrm{m}$. Four independent experiments were performed. GAPDH siRNA quantitation is provided in Supplementary Figure S4.

of npS9 GSK3 $\beta$ was detected (Figure 8B). The 12B2 sandwich ELISAs were then used to quantitatively measure the amount of npS9 GSK3 $\beta$ following calyculin A treatment. A significant reduction in the amount of npS9 GSK3 $\beta[t(3)=6.43, p=0.008]$ occurred after calyculin A treatment. Based on the recombinant npS9 GSK3 $\beta$ standard curve the control samples contained $5.2 \pm 0.12 \mathrm{ng}$ and treated samples contained $4.0 \pm 0.11 \mathrm{ng}$
npS9 GSK3 $\beta$ (per $60 \mu \mathrm{g}$ total protein; Figure 8C). The reduction in npS9 GSK3 $\beta$ levels was further confirmed by the qualitative reduction of $12 \mathrm{~B} 2$ reactivity in HEK293T cells treated with calyculin A (Figure 8D).

To determine whether protein phosphatase treatment caused reductions in GSK3 $\beta$ kinase activity, we ran the same lysates in a kinase activity assay using 12B2 to capture GSK3 $\beta$ 
A
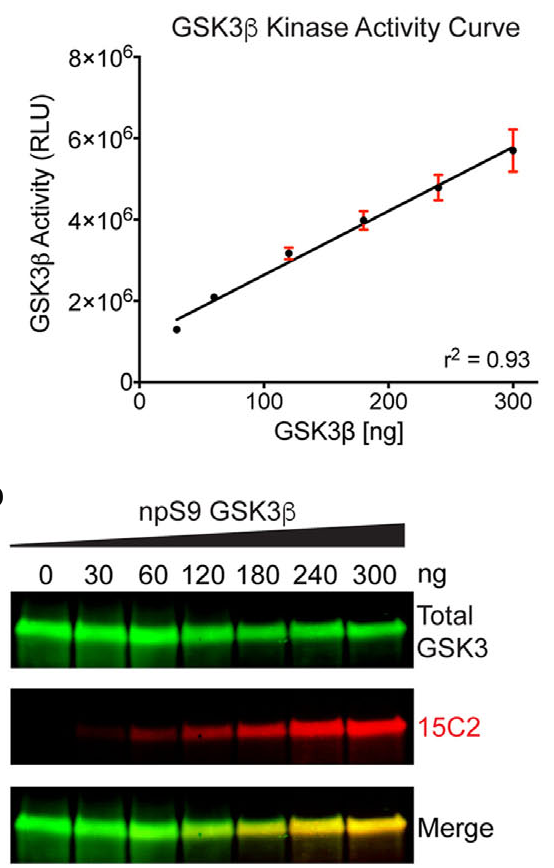

B
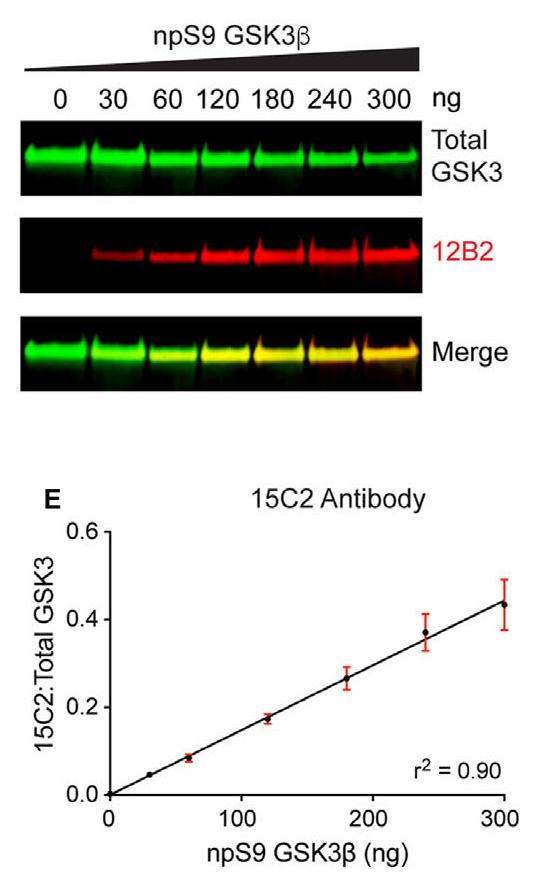

C

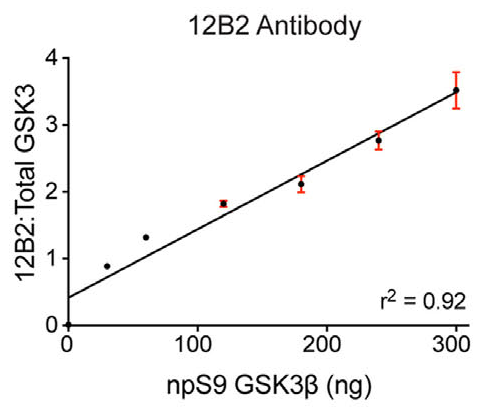

FIGURE 7 | Detection of recombinant npS9 GSK3 $\beta$ with $12 B 2$ and $15 C 2$ antibodies is linear and correlates with kinase activity. (A) The level of GSK3 $\beta$ kinase activity with 30, 60, 120, 180, 240, and 300 ng of npS9 GSK3 ("active") was measured using an in vitro GSK3 $\beta$ kinase activity assay and there was a linear increase in kinase activity with increasing amounts of GSK3 $\beta\left(r^{2}=0.93\right)$. Three independent experiments were performed. (B) For western blotting, recombinant GSK3 $\beta$ was incubated with alkaline phosphatase to generate nonphosphoS9 GSK3 $\beta$ or incubated with Akt 1 to generate phosphoS9 GSK3 $\beta$, and then $0,30,60$, $120,180,240$, or $300 \mathrm{ng}$ of npS9 GSK3 $\beta$ was mixed with $300,240,180,120,60$, or 0 ng of pS9 GSK3 $\beta$ to bring the total protein content to 300 ng/lane. The blot was probed with $12 \mathrm{~B} 2$ (red) and total GSK3 $\alpha / \beta$ antibodies (green). (C) Quantitation of signal from $12 \mathrm{~B} 2$ shows a linear increase in reactivity with increasing npS9 GSK3 $\beta$ amount $\left(r^{2}=0.92\right)$. (D) The same samples were probed with $15 \mathrm{C} 2$ (red) and total GSK3 $\alpha / \beta$ antibodies (green). (E) Quantitation of signal from $15 \mathrm{C} 2$ shows a linear increase in reactivity with increasing npS9 GSK3 $\beta$ amount $\left(r^{2}=0.90\right)$. It is notable that both $12 \mathrm{~B} 2$ and $15 \mathrm{C} 2$ signals also showed a direct correlation with GSK3 $\beta$ activity levels (12B2: $r=0.99, p=0.0002 ; 15 \mathrm{C} 2: r=0.99, p<0.0001)$. Four independent experiments were performed.

from the samples. Serial dilution of recombinant GSK3 $\beta$ enzyme produced a linear signal $\left(r^{2}=0.97\right.$; Figure 9A), and all experimental lysate samples were within the linear range. The activity of GSK3 $\beta$ was significantly reduced in calyculin A treated cells compared to control cells [calyculin A treatment factor: $F_{(1,12)}=13.84, p=0.003$; TCS treatment factor: $F_{(1,12)}=156.5, p<0.0001$; interaction factor: $F_{(1,12)}=16.59, p=0.002$; Figure 9B]. Interpolation from the recombinant GSK3 $\beta$ enzyme activity curve with known amounts of GSK3 $\beta$ (Figure 9A) indicates that the control samples contained $29 \mathrm{ng}$ active GSK $3 \beta$ and the calyculin A treated samples contained 15 ng active GSK3 $\beta$ (lysate samples were used at $60 \mu \mathrm{g}$ total protein/well). Treatment with TCS-2002, the potent GSK3 $\beta$ inhibitor, completely blocked kinase activity confirming GSK3 $\beta$ produced the signal (Figure 9B).

\section{Protein Phosphatases Dephosphorylate S9/21 in GSK3 $\beta / \alpha$ Independent of the Akt Pathway}

To further define the mechanisms of protein phosphatasemediated regulation of GSK3 we explored whether protein phosphatases modify S9/21 independent of the Akt pathway (Figure 10). Treatment of HEK293T cells with AZD-5363 (1 $\mu \mathrm{M})$, an Akt inhibitor (Davies et al., 2012; Li et al., 2013), caused a robust increase in npS9 GSK3 $\beta$ as detected with $12 \mathrm{~B} 2$ [Figures 11A,B; $\left.F_{(3,12)}=69.97, p<0.0001\right]$ and an increase in both npS GSK3 $\alpha$ and $\beta$ as detected with 15C2 [Figures 11DF; $\left.F_{(3,12)}=67.17, p<0.0001\right]$ when compared to controls. As expected, this indicates that blocking Akt activity leads to the accumulation of npS GSK3. Treatment of cells with calyculin A $(10 \mathrm{nM})$ caused a significant reduction in $\mathrm{npS} 9 \mathrm{GSK} 3 \beta$ as detected with 12B2 (Figures 11A,B) and a reduction in both npS GSK $3 \alpha$ and $\beta$ as detected with 15C2 (Figures 11D-F) when compared to controls. This confirms that inhibiting phosphatase activity allows phospho-S9/21 GSK3 to accumulate, but this can occur through two pathways because phosphatases can directly dephosphorylate both Akt (increasing phospho-Akt levels) and GSK3 (decreasing nonphospho-GSK3 levels) (Figure 10). To establish whether protein phosphatases dephosphorylate GSK3 at S9/21 independent of the Akt pathway, we first blocked Akt activity with AZD-5363 (for $1 \mathrm{~h}$ ) and then calyculin A was added (for $30 \mathrm{~min}$ ) to inhibit protein phosphatases. This treatment paradigm produced a significant reduction in npS9 GSK3 $\beta$ as indicated by $12 \mathrm{~B} 2$ and both $\operatorname{npS} \operatorname{GSK} 3 \alpha$ and $\beta$ as detected by 
A

12B2 Sandwich ELISA:

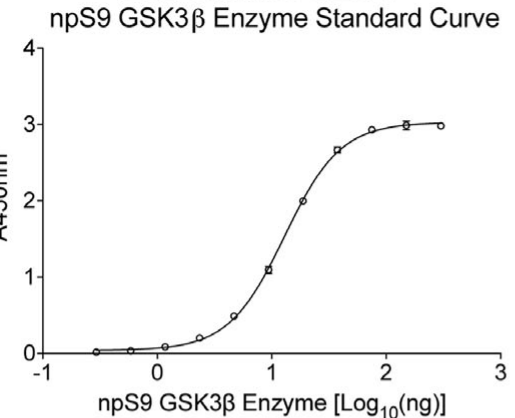

C

12B2 Sandwich ELISA: Calyculin A Treatment

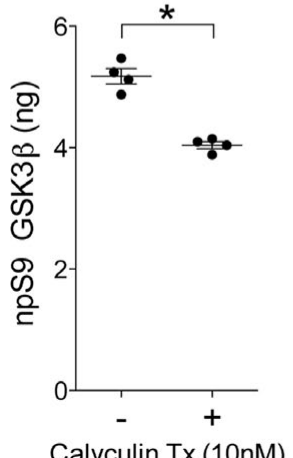

Calyculin Tx (10nM)
D
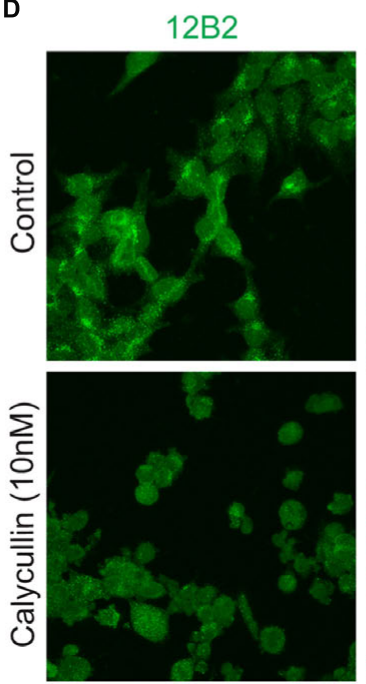

B

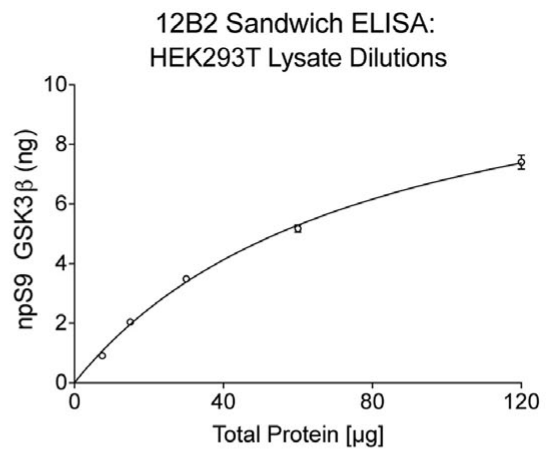

Total GSK3ß
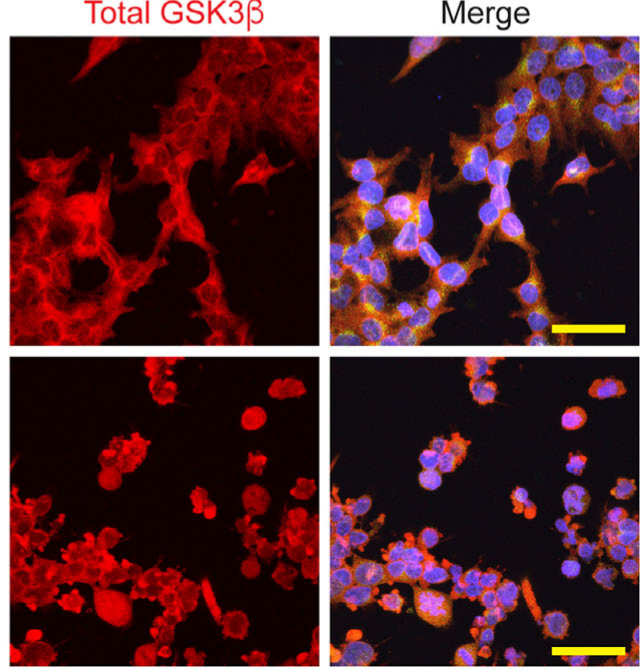

FIGURE 8 | Treating cells with protein phosphatase inhibitor decreases npS9 GSK3 $\beta$ in cells. (A) A standard curve of dephosphorylated GSK3 $\beta$ protein captured with 12B2 antibody was used for quantitative sandwich ELISAs $\left(r^{2}=0.999\right)$. (B) Untreated HEK293T lysates assayed in 12B2 sandwich ELISAs at 120, $60,30,15$, and $7.5 \mu \mathrm{g}$ total protein/well produces a linear dose response curve $\left(r^{2}=0.988\right)$. Interpolation using the standard curve in (A) indicates that the lysate samples contain 7.4, 5.2, 3.5, 2.0, and $0.9 \mathrm{ng}$ of npS9 GSK3 $\beta$, respectively. (C) HEK293T cells were either untreated (-) or treated with $10 \mathrm{nM}$ calyculin A for 30 min $(+)$ to reduce npS9 GSK3 $\beta$ levels ( $n=4$ independent experiments). The lysates were used in $12 B 2$ sandwich ELISAs. A significant reduction in npS9 GSK3 $\beta$ levels was detected in calyculin A (10 nM) treated cells compared to untreated cells $\left({ }^{*} p<0.05\right.$, unpaired $t$-test, two-tailed). The amount of npS9 GSK3 $\beta$ was quantitatively determined by interpolation using the recombinant GSK3 $\beta$ standard curve in (A). (D) Immunofluorescence for 12 B2 (green) showed an apparent qualitative reduction in npS9 GSK3 $\beta$ levels in HEK cells treated with calyculin A when compared to control cells. Cells were also stained with total GSK3 $\alpha / \beta$ (red) and DAPI. Scale $\operatorname{bar}=25 \mu \mathrm{m}$.

15C2 (Figures 11D-F) when compared to AZD-5363 alone. Furthermore, we observed the opposite result when blots were probed with a pS9 GSK3 $\beta$ antibody [Figure 11C, $F_{(3,12)}=46.79$, $p<0.0001]$. The AZD-5363 alone treatment resulted in increased active Akt levels [i.e., pT308 and pS473 Akt; Supplementary Figures S5A-C, pT308: $F_{(3,12)}=20.13, p<0.0001 ; \mathrm{pS} 473$ : $\left.F_{(3,12)}=7.699, p=0.004\right]$ and increased npS GSK3 levels demonstrating that we effectively blocked Akt activity at the dose used (ineffective inhibition would lead to reduced npS GSK3 and increased pS GSK3 in the presence of elevated active Akt levels). It is noteworthy that neither total GSK3 $\alpha / \beta$ [Total $\alpha: F_{(3,12)}=1.824, p=0.20$; Total $\beta: F_{(3,12)}=0.926$, $p=0.46]$ nor total Akt levels $\left[F_{(3,12)}=0.955, p=0.45\right]$ were significantly affected with these treatments (Supplementary Figures S5D,E).

\section{DISCUSSION}

The GSK3 $\beta$ enzyme is one of the most widely studied S/T kinases because of its role in several biological processes (Kim and Kimmel, 2006; Kockeritz et al., 2006; Forde and Dale, 2007; Hur and Zhou, 2010; Medina and Wandosell, 2011; Beurel et al., 2015) and disease states (Hernandez and Avila, 2008; Cadigan and Peifer, 2009; Golpich et al., 2015; Lal et al., 2015; Li et al., 2015; O’Leary and Nolan, 2015). Not surprisingly, GSK3 $\beta$ regulation is tightly controlled by several mechanisms including phosphorylation, substrate priming, truncation, protein complex association and subcellular localization (Medina and Wandosell, 2011). Phosphorylation is the most prominent and wellunderstood regulatory mechanisms, and phosphorylation of S9 in GSK3 $\beta$ (S21 in GSK3 $\alpha$ ) is a dominant negative 
A

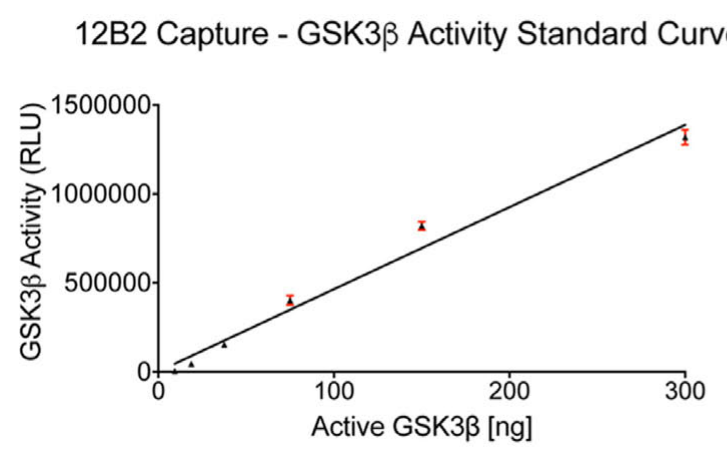

B

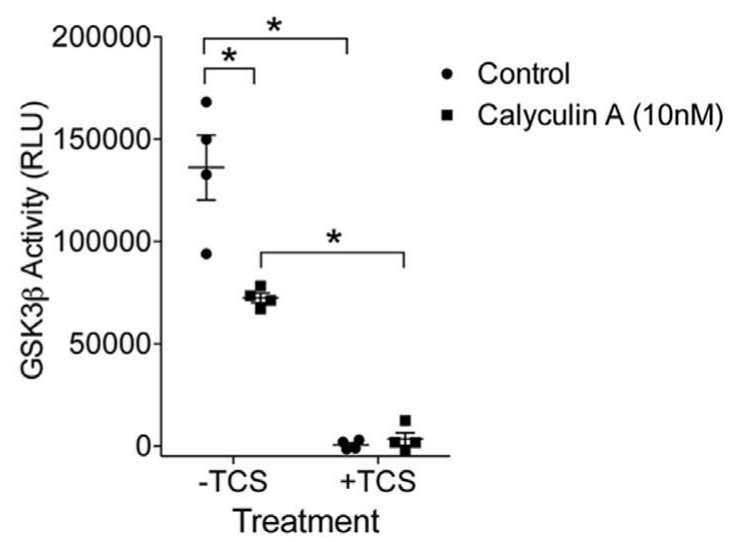

FIGURE 9 | Protein phosphatase inhibition significantly reduces GSK3 $\beta$ kinase activity in cells. (A) A standard curve of active GSK3 $\beta$ enzyme ( 300 $9.4 \mathrm{ng}$ ) confirmed the signal in the experimental samples was within the linear range of detection in this assay $\left(r^{2}=0.97\right)$. Experiment was repeated three times. (B) Calyculin A treated cells showed a significant reduction in GSK3 $\beta$ kinase activity compared to control cells (the -TCS sample sets; all samples were used at $60 \mu \mathrm{g}$ total protein/well). Interpolation from the recombinant GSK3 $\beta$ enzyme activity curve with known amounts of active GSK3 $\beta$ indicated that the control samples contained $29 \mathrm{ng}$ of active GSK3 $\beta$ and calyculin A treated cells contained $15 \mathrm{ng}$. Addition of TCS-2002 (0.1 mM; +TCS), a potent GSK3 $\beta$ inhibitor, completely blocked kinase activity in control and calyculin A treated cells $\left({ }^{*} p<0.05\right.$, two-way ANOVA with Holm-Sidak post hoc test, two-tailed). Note that the same lysate samples used here were used in Figure 8. This experiment was repeated four times.

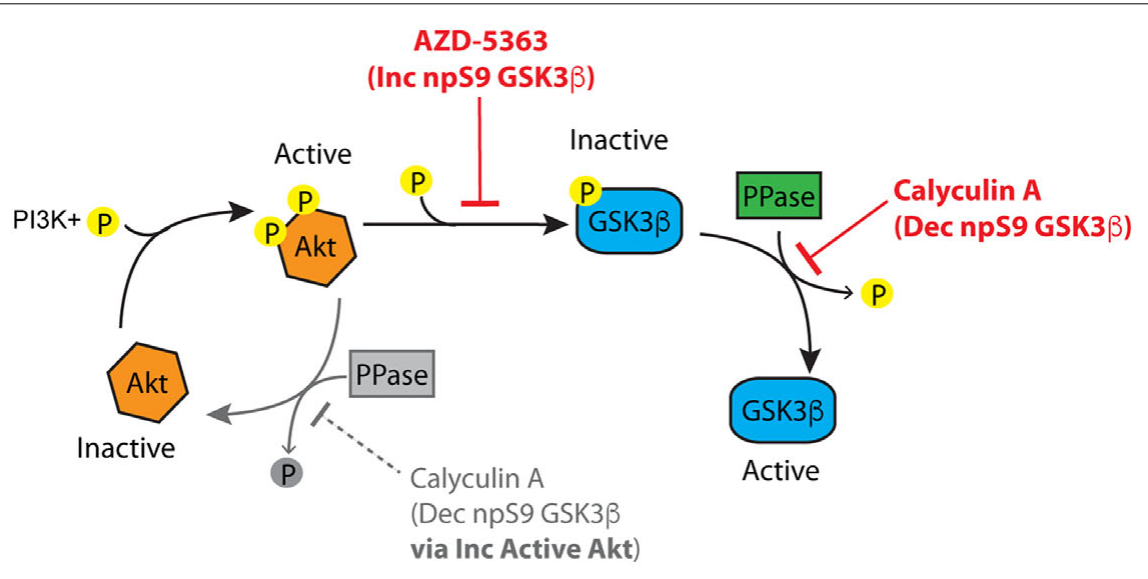

FIGURE 10 | The Akt-protein phosphatase signaling pathway involved in regulating GSK3 $\beta$ phosphorylation. Active Akt (i.e., phosphorylated) inactivates GSK3 $\beta$ by phosphorylation at S9. Protein phosphatases can modulate GSK3 $\beta$ phosphorylation at S9 via two routes. (1) Protein phosphatases inactivate Akt by dephosphorylation, and (2) protein phosphatases activate GSK3 $\beta$ by directly dephosphorylating S9. Inhibition of Akt (with inhibitors such as AZD-5363) increases non-phosphorylated GSK3 $\beta$ by suppressing Akt-mediated phosphorylation of GSK3 $\beta$. Inhibition of protein phosphatases (with inhibitors such as calyculin A) causes a decrease in non-phosphorylated GSK3 $\beta$ through the Akt pathway by increasing active Akt (the grayed portion of the Akt cycle). Protein phosphatase inhibition also leads to decreased non-phosphorylated GSK3 $\beta$ independent of Akt by directly dephosphorylating S9 in GSK3 $\beta$. If an Akt inhibitor is applied followed by a protein phosphatase inhibitor the Akt-independent pathway can be evaluated.

regulatory mechanism because the pS9 region competitively blocks substrate docking by mimicking primed substrates. In general, when S9 is not phosphorylated, the enzyme is typically considered "active" because other modifications such as phosphorylation of tyrosine 216 (or tyrosine 276 in GSK $3 \alpha$ ) appear to occur at near stoichiometric levels and during translation in a chaperone-dependent mechanism (Hughes et al., 1993; Wang et al., 1994a; Cohen and Goedert, 2004; Cole et al., 2004). However, there are other Ser/Thr residues in GSK3 $\beta$, such as T43, T390 and S389, that are targets of other kinases (i.e., Erk and/or p38 MAPK) and modulate the activity of GSK3 $\beta$ as well (Ding et al., 2005; Thornton et al., 2008). Thus, levels of npS9 GSK3 $\beta$ can generally be a useful surrogate marker for the amount of GSK3 in an "active-state," and here we show that $12 \mathrm{~B} 2$ or 15C2 reactivity in western blots correlates well with kinase activity (at least using recombinant proteins in vitro). However, the npS GSK3 antibodies do not directly speak to kinase activity levels and GSK3 $\beta$ activity should be directly assayed when possible. To this end, we demonstrate that $12 \mathrm{~B} 2$ 
A

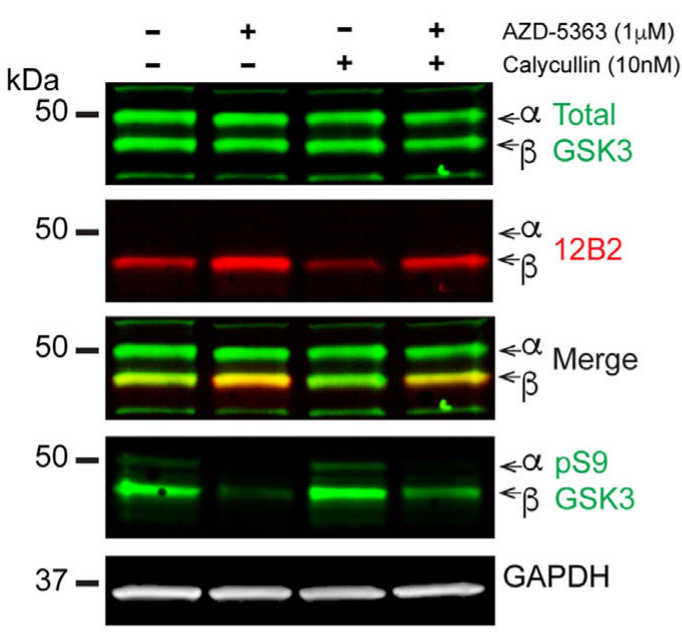

D

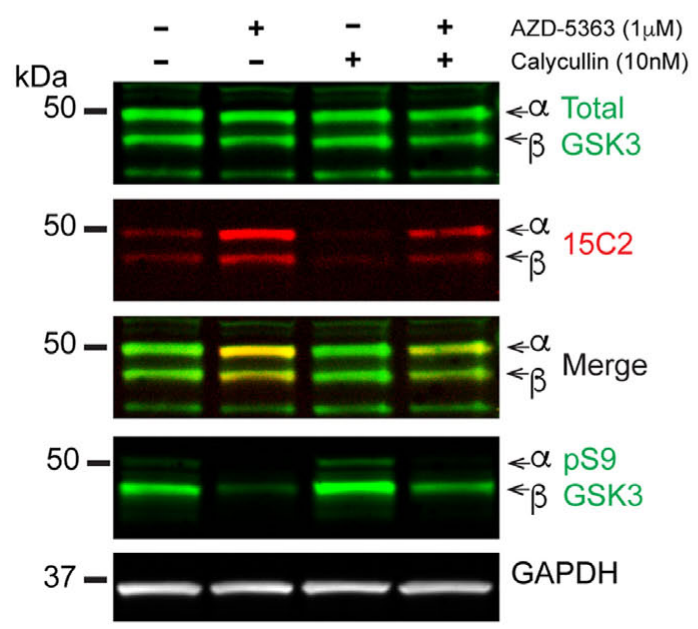

B

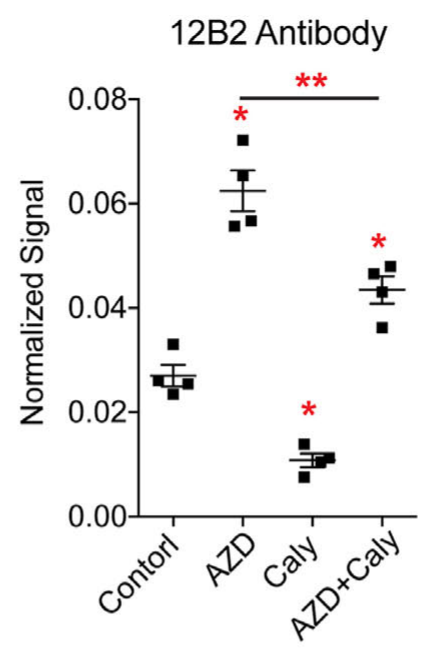

E

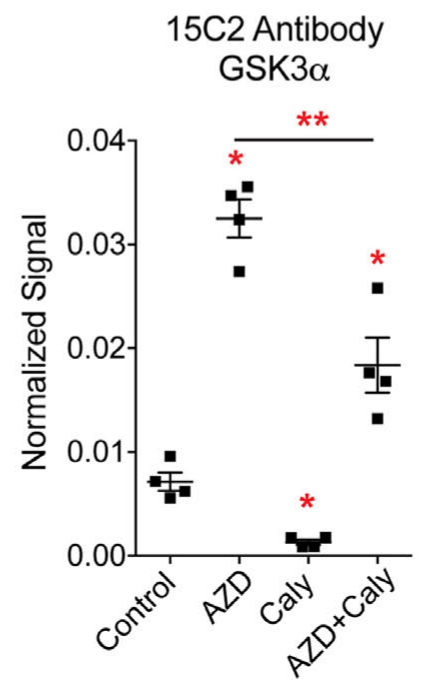

C

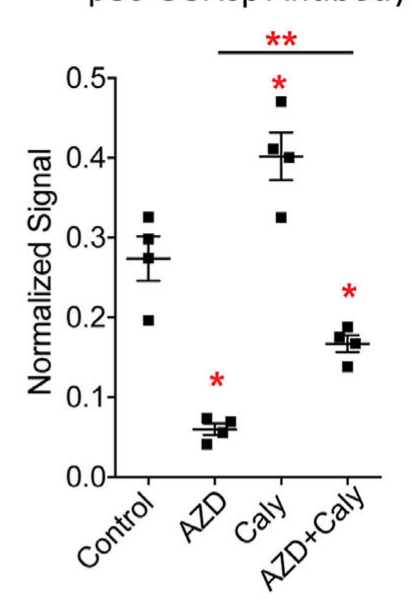

$\mathbf{F}$

15C2 Antibody GSK3 $\beta$

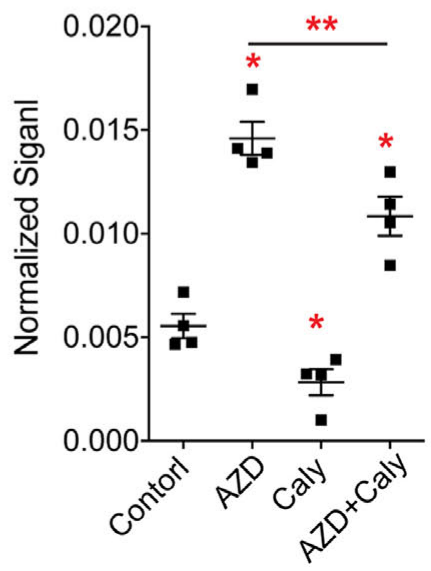

FIGURE 11 | Protein phosphatases regulate GSK3 $\beta$ phosphorylation independent of Akt signaling. HEK293T cells were treated with an Akt inhibitor (AZD-5363, $1 \mu \mathrm{M}$ ), a protein phosphatase inhibitor (calyculin A, $10 \mathrm{nM}$ ) or the Akt inhibitor followed by the phosphatase inhibitor. Four independent experiments were run. (A) Western blots of samples were probed with $12 B 2$ (npS9-GSK3 $\beta$ specific), total GSK3 $\alpha / \beta$, pS9-GSK3 $\beta$ and GAPDH (loading control). (B) Quantitation

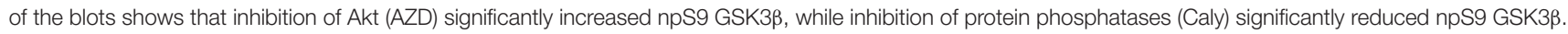
When Akt signaling was blocked first and then the phosphatase inhibitor was applied (AZD + Caly) a significant reduction in the level of npS9 GSK3 $\beta$ occurred when

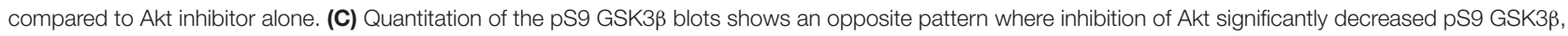
while inhibition of phosphatases significantly increased pS9 GSK3ק. When Akt signaling was blocked and then the phosphatase inhibitor was applied a significant increase in the level of pS9 GSK3 $\beta$ occurred when compared to Akt treatment alone. (D) Western blots of samples were probed with 15C2 (npS9-GSK3 $/ \beta$ specific), total GSK3 $\alpha / \beta$, pS9-GSK3 $\beta$ and GAPDH (loading control). (E,F) Quantitation of the blots shows that inhibition of Akt significantly increased npS9 GSK3 $\alpha$ and $\beta$, while inhibition of protein phosphatases significantly reduced npS9 GSK3 $\alpha$ and $\beta$. When Akt signaling was blocked and then the phosphatase inhibitor was applied a significant reduction in the level of npS9 GSK3 $\beta$ and npS21 GSK3 $\alpha$ occurred when compared to Akt inhibitor alone. Collectively, these results suggest protein phosphatases dephosphorylate Ser9/21 independent of Akt signaling. All bands are normalized to GAPDH. All groups were statistically significant from the others in $(\mathbf{B}, \mathbf{C}, \mathbf{E}, \mathbf{F})$, but only $* p<0.05$ vs. control and ${ }^{* *} p<0.05$ vs. AZD alone are indicated to simplify the graph and highlight the critical comparisons (one-way ANOVA, Holm-Sidak post hoc test). Total GSK3 $\alpha / \beta$ levels, total Akt and phospho-Akt immunoblots from these experiment are displayed in Supplementary Figure S5.

can be applied in assays that allow direct measurement of GSK3 $\beta$ kinase activity in experimental lysates, and that the same reagent directly measures npS9 GSK3 $\beta$ in several assay formats.

\section{Considerations for Producing Stable, High-Quality Monoclonal Antibodies}

Our understanding is that npS9 GSK3ß reagents were difficult to obtain by other groups and companies. We used a relatively 
unique immunization approach by combining a normal peptide, a tandem repeat peptide and an arginine enantiomer peptide. The tandem peptide provides more antigens specifically centered on the residue of interest, while arginine enantiomers are known to enhance antigenicity (Benkirane et al., 1993; Guichard et al., 1994). We rule out antibodies that react against KLH, neoepitopes in the tandem peptide and the $\mathrm{D}$-arginine by using normal GSK3 $\beta$ peptides not conjugated to KLH in all screening assays. Moreover, we place a great deal of importance on identifying specificity early in the process. For example, assessing differences in reactivity for $n p S 9$ GSK3 $\beta$, pS9 GSK3 $\beta$ and $n p S 21$ GSK3 $\alpha$ begins at the fusion stage. We also require relatively robust serum titer signal (1:25,000 or greater dilution), high levels of reactivity in subsequent ELISAs (absorbance $>1.0$ ), stability after repeated freeze/thaw cycles, and mycoplasma negativity to consider a line stable and of sufficient quality. Typically, we subclone lines 2-3 times every time we retrieve a clone from long-term storage to ensure clone stability and consistency. Overall, these criteria help establish high quality, sustainable lines for producing reagents indefinitely.

\section{Advantages of the New GSK3 Antibody Reagents}

Despite the importance of GSK3 and widespread interest in GSK3, reagents for directly measuring npS9/21 GSK3 $\beta / \alpha$ (i.e., the so-called "active" form) did not exist. Currently available antibodies allow only indirect assessment of changes in GSK3 activation by looking at the phosphorylated N-terminal serine residues and many of them lack a high degree of specificity. We provide rigorous, detailed characterization of two novel monoclonal antibodies. The 12B2 antibody specifically detects npS9 GSK3 $\beta$, and lacks reactivity when S9 is phosphorylated and does not react with GSK $3 \alpha$ proteins. The $15 \mathrm{C} 2$ antibody works similarly with GSK3 $\beta$ but also detects npS21 GSK $3 \alpha$ making it useful for also studying GSK3 $\alpha$ regulation. It is noteworthy that neither of these antibodies showed detectable reactivity against phospho-S9/21 peptides in ELISAs (even when high antibody concentrations or large amounts of peptides were used) or against in vitro phosphorylated recombinant GSK3 in western blotting (up to $300 \mathrm{ng}$ protein). Evaluating total GSK3 $\beta$ levels is not required with these new reagents when equivalent samples are used, but this may remain a valuable assessment if determining whether experimental conditions alter both the amount of npS9 GSK3 $\beta$ and total GSK3 $\beta$ is desired. All of the reagents detect GSK3 enzymes in human, mouse and rat, as well a number of commonly used human, mouse and rat cell types, which is expected considering the high homology across these species. The high sequence homology in this region goes across many species (both vertebrates and invertebrates) (Forde and Dale, 2007), which likely expands the usefulness of these reagents.

The fact that these antibodies work in several assays further highlights their advantages. We tested these antibodies in indirect ELISAs, western blotting, immunoprecipitations, cell culture ICF, and tissue section IHC using a range of samples including synthetic peptides, recombinant GSK3 $\beta$ and $\alpha$, as well as human and rodent cells and tissues. Providing npS9 GSK3-specific reagents will allow researchers versatility and the added benefit of using the same reagents in several assay formats. The fact that these antibodies work in both biochemical assays and immunostaining assays in cultured cells and tissue sections represents another advantage because identifying subcellular localization of changes in npS9 GSK3 $\beta$ can be directly related to changes in protein levels and kinase activity. Interestingly, the immunofluorescence studies in cultured cells showed a predominance of punctate staining with npS9 GSK3 $\beta$ antibodies (particularly 12B2), which may represent signalosomes or other multi-component complexes containing npS9 GSK3 $\beta$ enzymes (Bilic et al., 2007; Cadigan and Peifer, 2009). In fact, the siRNA studies clearly show that these puncta are reduced in cells, confirming they contain npS9 GSK3 $\beta$. Thus, the reagents described here provide new all-in-one reagents for directly measuring npS9 GSK3 $\beta$ and GSK3 $\beta$ kinase activity levels that exhibit great assay versatility, subcellular localization and cross-species utilization (Table 1).

The most compelling data supporting the use of these antibodies to provide biological insights are those confirming that they directly measure, in a linear fashion, the amount of npS9 GSK3 $\beta$. We demonstrate that these reagents detect changes in the amount of npS9 GSK3 $\beta$ and that the signals on immunoblots correlate very well with the kinase activity of GSK3 $\beta$ using recombinant proteins and experimentally induced GSK3 $\beta$ inhibition (e.g., calyculin treated cells). Moreover, the use of a recombinant protein standard curve in the sandwich ELISAs and the kinase activity assays allows quantitation of unknown amounts of active GSK3 $\beta$

TABLE 1 | Summary of GSK3 $\beta$ antibody performance in assays tested in the current work.

\begin{tabular}{|c|c|c|c|c|c|c|c|c|c|c|c|}
\hline $\begin{array}{l}\text { Antibody } \\
\text { (Isotype) }\end{array}$ & $\begin{array}{c}\text { Peptide } \\
\text { Indirect } \\
\text { ELISA }\end{array}$ & $\begin{array}{c}\text { Rec Prot } \\
\text { WB }\end{array}$ & $\begin{array}{c}\text { Brain } \\
\text { Lysate WB }\end{array}$ & $\begin{array}{l}\text { Lysate } \\
\text { IP }\end{array}$ & $\begin{array}{c}\text { Rec Prot } \\
\text { sELISA }\end{array}$ & $\begin{array}{l}\text { Lysate } \\
\text { sELISA }\end{array}$ & $\begin{array}{c}\text { IHC (rat } \\
\text { brain) }\end{array}$ & $\begin{array}{c}\text { IHC } \\
\text { (human } \\
\text { brain) }\end{array}$ & $\begin{array}{c}\text { ICF } \\
\text { (culture) }\end{array}$ & $\begin{array}{c}\text { WB } \\
\text { (activity } \\
\text { assay } \\
\text { samples) }\end{array}$ & $\begin{array}{c}\text { Kinase } \\
\text { Activity } \\
\text { Assay }\end{array}$ \\
\hline $\begin{array}{l}\text { 12B2 } \\
\text { (IgG1) }\end{array}$ & $\beta>>\alpha$ & $\beta$ only & $\beta$ only & Yes ( $\beta$ ) & ++ & \multirow{2}{*}{$\begin{array}{c}\text { Yes } \\
r^{2}=0.99 \\
\text { nd }\end{array}$} & +++ & +++ & ++ & \multirow{2}{*}{$\begin{array}{l}r^{2}=0.92 \\
p<0.0001 \\
r^{2}=0.90 \\
p<0.0001\end{array}$} & Yes \\
\hline $\begin{array}{l}\text { 15C2 } \\
\text { (IgG1) }\end{array}$ & $\beta<\alpha$ & $\beta<\alpha$ & $\beta<\alpha$ & Yes $(\alpha / \beta)$ & - & & +++ & +++ & ++ & & nd \\
\hline
\end{tabular}

- poor or no signal, + weak signal, ++ moderate signal, +++ strong signal and ++++ best signal relative to other antibodies. Rec Prot, recombinant protein; ELISA, enzyme linked immunosorbent assay; WB, western blot; IP, immunoprecipitation; sELISA, sandwich ELISA; IP, immunoprecipitation; IHC, immunohistochemistry; ICF, immunocytofluorescence; nd, not determined. 
and GSK3 $\beta$ activity levels in whole cell lysates. A few approaches are currently used to measure GSK3 $\beta$ activity in experimental lysate samples that often involve combining immunoprecipitation of total GSK3 $\beta$ and in vitro GSK3 $\beta$ activity assays (Welsh et al., 1997; Bijur and Jope, 2001; Bowley et al., 2005). Thus, these reagents have a distinct advantage over currently available reagents because other reagents do no target the npS9 (or "active") form of GSK3 $\beta$, and subsequently the new antibodies enhance our ability to study GSK3 regulation.

The performance of each antibody was remarkably similar across assays, but some differences were observed. For instance, the synthetic peptide indirect ELISAs showed moderate affinity differences between GSK3 $\beta$ and GSK3 $\alpha$ with 12B2, while $15 \mathrm{C} 2$ showed a stronger reaction with GSK $3 \alpha$ over GSK3 $\beta$ peptides. However, assays that used the full-length protein showed the differential affinity for GSK3 $\beta$ and $\alpha$ was substantial for 12B2, and $15 \mathrm{C} 2$ reacted equally as well with both forms of GSK3. Once lysate samples were used, the differential reactivity between GSK $3 \beta$ and GSK $3 \alpha$ were quite robust with no $12 \mathrm{~B} 2$ reactivity for GSK $3 \alpha$ under the conditions used. Overall, 12B2 produced results demonstrating it is specific to npS9 GSK3 $\beta$ isoform, while $15 \mathrm{C} 2$ is specific to npS9 GSK3 $\beta$ and npS21 GSK $3 \alpha$.

\section{Novel GSK3 $\beta$ Antibodies Demonstrate that Protein Phosphatases Reduce npS9 GSK3 $\beta$ Levels and Kinase Activity through an Akt-Independent Pathway}

Protein phosphatases are thought to regulate GSK3 $\beta$ activity through dephosphorylation of S9, where increased phosphatase activity leads to increased GSK3 $\beta$ activity, and likewise, protein phosphatase inhibition causes GSK3 $\beta$ inhibition by reducing nonphospho-S9 GSK3 $\beta$. Indeed, this regulatory pathway appears to play a role in GSK3 $\beta$ activation under several biological contexts, including cell excitability, survival of leukemic progenitors, insulin signaling, growth factor signaling, and motor protein regulation, among others (Sutherland et al., 1993; Leung-Hagesteijn et al., 2001; Morfini et al., 2004; Lee et al., 2005; Szatmari et al., 2005; Bertrand et al., 2012; Ma et al., 2012). However, protein phosphatases also may influence GSK3 $\beta$ phosphorylation through the Akt pathway (Millward et al., 1999; Bononi et al., 2011). In the Akt pathway, stimulation of the phosphoinositide 3-kinase/Akt pathway leads to activation of Akt via phosphorylation of T308 and S473 residues, and then active Akt phosphorylates GSK3 $\beta / \alpha$ at S9/21 (Gold et al., 2000; Varea et al., 2010; Majewska and Szeliga, 2016). Protein phosphatases (in particular protein phosphatase 2A) dephosphorylate Akt leading to Akt inactivation, and subsequently increased active GSK3 $\beta / \alpha$ via the loss of Akt-mediated S9/21 phosphorylation (Millward et al., 1999; Bononi et al., 2011).

Previous studies were unable to directly demonstrate that protein phosphatases-mediated effects were due to changes in the npS9 GSK3 $\beta$ because such reagents did not exist. Furthermore, we set out to determine whether protein phosphatases dephosphorylate GSK3 $\beta / \alpha$ at S9/S21 independent of Akt signaling. Our results using both 12B2 and 15C2 suggest that protein phosphatases decrease npS9/21 GSK3 $\beta / \alpha$ levels via direct dephosphorylation that is independent of the Akt pathway. As expected, blocking Akt activity robustly increased levels of npS GSK3 because Akt could no longer phosphorylate GSK3, despite an elevation in active Akt levels (i.e., pT308 and pS473 Akt). When Akt was inhibited to eliminate contributions of the Akt pathway prior to application of protein phosphatase inhibitor, there was a significant reduction in npS GSK3 and increase in pS GSK3 suggesting that GSK3 dephosphorylation by protein phosphatases occurs independent of Akt pathway. We also show that the reduced levels of npS9 GSK3 $\beta$ in HEK293 cells treated with protein phosphatase inhibitor causes a reduction in GSK3 $\beta$ kinase activity by using the $12 \mathrm{~B} 2 \mathrm{npS} 9 \mathrm{GSK} 3 \beta$ antibody. In fact, the same reagent was used to validate this biologically relevant mechanism of GSK3 $\beta$ regulation across several assay formats, including western blots, ELISAs, immunocytofluorescence and kinase activity assays. Thus, these reagents show strong inter-assay validation and should provide researchers the ability to directly and more accurately study GSK $3 \beta$ regulation and activity across many biological contexts.

\section{CONCLUSION}

The lack of reagents that specifically and directly assess the level of $n \mathrm{pS} 9 / 21 \mathrm{GSK} 3 \beta / \alpha$ has burdened the research community. Here, we provide the characterization of one monoclonal antibody that specifically reacts with GSK3 $\beta$ when S9 is not phosphorylated, as well as one antibody that also reacts with GSK3 $\alpha$ when S21 is not phosphorylated. Notably, these reagents will allow researchers to directly measure the level of npS GSK3 in experimental conditions using a wide range of assay formats. We provide evidence that these reagents will help researchers study GSK3 $\beta$ regulation in biological systems by demonstrating that protein phosphatase inhibition leads to reduced GSK3 $\beta$ activity via reductions in amount of npS9 forms of GSK3 $\beta$ independent of Akt signaling. Collectively, these reagents should provide significant advantages over existing reagents and will help to facilitate GSK3 $\beta$ research across many fields of biology. Finally, if changes in GSK3 $\beta$ activity are an important marker for a particular disease state, which is likely considering the involvement of GSK3 $\beta$ in several disease processes, these reagents may be extremely useful in developing diagnostic and/or biomarker assays for diseases.

\section{AUTHOR CONTRIBUTIONS}

TG and NK worked together on all aspects of this work and both approve the final version of the manuscript.

\section{FUNDING}

This work was supported by NINDS (R01NS082730, NK), NIA (R01AG044372, NK) and the Jean P. Schultz Biomedical Research Endowment at MSU (NK). 


\section{ACKNOWLEDGMENTS}

We would like to dedicate this work to Dr. Lester "Skip" Binder for his unmatched prowess in creating monoclonal antibodies. Without his tutelage, the generation of these antibodies would not have been possible. We are grateful to Dr. Thomas Beach and the Banner Sun Health Research Institute Brain and Body Donation Program of Sun City, Arizona for the provision of human biological materials.

\section{SUPPLEMENTARY MATERIAL}

The Supplementary Material for this article can be found online at: http://journal.frontiersin.org/article/10.3389/fnmol. 2016.00123/full\#supplementary-material

FIGURE S1 | Hybridoma fusion and subcloning procedures. (A-C) Indirect ELISA titer of serum from immunized animals after the 3rd (A) and 6th (B) immunization boost. Animal T10 and N00 were used for fusions because they produced the strongest reactivity after the 3rd and 6th boosts, respectively. (C,D) The fusion cultures were screened against npS9 GSK3 $\beta$, pS9 GSK3 $\beta$ and npS21 GSK3 $\alpha$ peptides. *indicates reactivity with npS9 much greater than npS21 GSK3 $\alpha$ and no reactivity with pS9 GSK3 $\beta$; **indicates reactivity with more npS21 GSK3 $\alpha$ than npS9 GSK3 $\beta$ and no reactivity with pS9 GSK3 $\beta$. The 12B2 (C) and15C2 (D) cultures were continued to the first subclone. Subsequent subclone cultures were similarly screened against these peptides in indirect ELISAs (using same method) to evaluate specificity during the cloning process (data not shown). We typically require that the percent of reactive clone wells should be $\geq 95 \%$ by the third subclone (12B2 $=99 \%$ and $15 \mathrm{C} 2=100 \%$ ). (E) Phosphorylation at serine 9 of the pS9 GSK3 $\beta$ peptide was confirmed using a pS9 GSK3 $\beta$-specific antibody in indirect ELISAs.

\section{FIGURE S2 | 12B2 and 15C2 label npS GSK3 isoforms in multiple cell} types. (A) Cell lysates from SH-SY5Y neuroblastoma cells (human), HEK293T cells (human), primary neurons (rat), U373 glioblastoma cells (human), and Neuro-2a neuroblastoma cells (mouse, N2a) were probed with total GSK3 $\alpha / \beta$ (green) and 12B2 (red) antibodies to detect npS9 GSK3 $\beta$. Much like the brain lysates in Figure 3, 12B2 specifically labels only npS9 GSK3 $\beta$ in all cell types, but

\section{REFERENCES}

Aberle, H., Bauer, A., Stappert, J., Kispert, A., and Kemler, R. (1997). beta-catenin is a target for the ubiquitin-proteasome pathway. EMBO J. 16, 3797-3804. doi: 10.1093/emboj/16.13.3797

Beach, T. G., Adler, C. H., Sue, L. I., Serrano, G., Shill, H. A., Walker, D. G., et al. (2015). Arizona study of aging and neurodegenerative disorders and brain and body donation program. Neuropathology 35, 354-389. doi: 10.1111/neup.12189

Benkirane, N., Friede, M., Guichard, G., Briand, J. P., Van Regenmortel, M. H., and Muller, S. (1993). Antigenicity and immunogenicity of modified synthetic peptides containing $\mathrm{D}$-amino acid residues. antibodies to a $\mathrm{D}$-enantiomer do recognize the parent L-hexapeptide and reciprocally. J Biol. Chem. 268, 26279-26285.

Bertrand, J., Despeaux, M., Joly, S., Bourogaa, E., Gallay, N., Demur, C., et al. (2012). Sex differences in the GSK3beta-mediated survival of adherent leukemic progenitors. Oncogene 31, 694-705. doi: 10.1038/onc.2011.258

Beurel, E., Grieco, S. F., and Jope, R. S. (2015). Glycogen synthase kinase-3 (GSK3): regulation, actions, and diseases. Pharmacol. Ther. 148, 114-131. doi: 10.1016/j.pharmthera.2014.11.016

Bijur, G. N., and Jope, R. S. (2001). Proapoptotic stimuli induce nuclear accumulation of glycogen synthase kinase-3 beta. J. Biol. Chem. 276, 37436-37442. doi: $10.1074 /$ jbc.M105725200

Bilic, J., Huang, Y. L., Davidson, G., Zimmermann, T., Cruciat, C. M., Bienz, M., et al. (2007). Wnt induces LRP6 signalosomes and promotes varying amounts were detected in the difference cells (all loaded at $50 \mu \mathrm{g} / \mathrm{lane}$ ). (B) Cell lysates from the same cells were probed with total GSK3 $\alpha / \beta$ (green) and $15 \mathrm{C} 2$ (red) antibodies to detect npS9/21 GSK3 $\beta / \alpha$. Much like the brain lysates in Figure 3, 15C2 specifically labels both npS9 GSK3 $\beta$ and npS21 GSK3 $\alpha$ in all cell types, but varying amounts were detected in the difference cells (all loaded at $50 \mu \mathrm{g} /$ lane).

FIGURE S3 | Primary delete controls for cell culture immunofluorescence and tissue immunohistochemistry. (A) HEK293T cells were processed for immunofluorescence with the exception that the npS9 GSK3 $\beta$ (green channel) and total GSK3 $\alpha / \beta$ (red channel) primary antibodies were omitted (cells were counterstained with DAPI, blue channel). A lack of staining confirms that the signals were due to reactivity with the primary antibodies and not artifacts from other components of the staining procedure or imaging cells with fluorescence. (B) Rat and human tissue sections were processed for immunohistochemistry with the exception that the npS9 GSK3 $\beta$ antibodies were omitted. A lack of staining confirms that the signals were due to reactivity with the primary antibody and not artifacts from processing tissue through the staining procedure. All scale bars in $\mathbf{( A , B )}$ are $50 \mu \mathrm{m}$.

FIGURE S4 | Effects of GAPDH siRNA in HEK293T Cells. HEK293T cells were treated with GAPDH siRNAs and probed with $12 \mathrm{~B} 2$ or $15 \mathrm{C} 2$ and total GSK3 $\beta / \alpha$ antibodies (see Figures 5A and 6A for blot images). (A) Quantification shows that GSK3 $\beta$ siRNA caused a reduction of $82 \%$ in signal for the GAPDH when compared to control cells. (B) Quantification of the GSK3 $\alpha$ and GSK3 $\beta$ bands with $15 \mathrm{C} 2$ (which labels both npS9 GSK3 $\beta$ and npS21 GSK3 $\alpha$ ) showed only minimal changes compared to controls $(-17 \%)$.

FIGURE S5 | Akt inhibitor and protein phosphatase inhibitor treatments affect Akt phosphorylation, but not total Akt or GSK3 levels. HEK293T cells were treated with an Akt inhibitor (AZD-5363, $1 \mu \mathrm{M}$ ), a protein phosphatase inhibitor (calyculin A, $10 \mathrm{nM}$ ) or the Akt inhibitor followed by the phosphatase inhibitor to demonstrate the potential utility of 12B2 and 15C2 in studying GSK3 regulation. Four independent experiments were run (same as Figure 11). (A) Western blots of samples were probed with pT308 Akt and pS473 Akt (active phospho-Akt), total Akt and GAPDH (loading control). (B,C) Quantitation of the blots shows that inhibition of Akt (AZD) significantly increased both (B) pT308 and (C) pS473 Akt. The fact that AZD caused upregulation of npS9/21 GSK3 $\beta / \alpha$ (see Figure 11) and increased active phospho-Akt (which would normally decrease npS GSK3 levels) confirms the effectiveness of the AZD dose. (D,E) None of the treatments significantly affected the levels of $(\mathbf{D})$ total Akt $(p=0.45)$, as well as $(\mathbf{E})$ total GSK $\alpha(p=0.20)$ or total GSK3 $\beta(p=0.46)$. All bands are normalized to GAPDH. (* $p<0.05$ vs. control; one-way ANOVA, Holm-Sidak post hoc test).

dishevelled-dependent LRP6 phosphorylation. Science 316, 1619-1622. doi: 10.1126/science. 1137065

Binder, L. I., Frankfurter, A., and Rebhun, L. I. (1985). The distribution of tau in the mammalian central nervous system. J. Cell Biol. 101, 1371-1378. doi: 10.1083/jcb.101.4.1371

Bononi, A., Agnoletto, C., De Marchi, E., Marchi, S., Patergnani, S., Bonora, M., et al. (2011). Protein kinases and phosphatases in the control of cell fate. Enzyme Res. 2011:329098.

Bowley, E., Mulvihill, E., Howard, J. C., Pak, B. J., Gan, B. S., and O’gorman, D. B. (2005). A novel mass spectrometry-based assay for GSK-3beta activity. BMC Biochem. 6:29. doi: 10.1186/1471-2091-6-29

Cadigan, K. M., and Peifer, M. (2009). Wnt signaling from development to disease: insights from model systems. Cold Spring Harb. Perspect. Biol. 1:a002881. doi: 10.1101/cshperspect.a002881

Chen, R. H., Ding, W. V., and Mccormick, F. (2000). Wnt signaling to betacatenin involves two interactive components. Glycogen synthase kinase-3beta inhibition and activation of protein kinase C. J. Biol. Chem. 275, 17894-17899.

Cohen, P., and Goedert, M. (2004). GSK3 inhibitors: development and therapeutic potential. Nat. Rev. Drug Discov. 3, 479-487. doi: 10.1038/ nrd1415

Cole, A., Frame, S., and Cohen, P. (2004). Further evidence that the tyrosine phosphorylation of glycogen synthase kinase-3 (GSK3) in mammalian cells is an autophosphorylation event. Biochem. J. 377, 249-255. doi: 10.1042/bj20 031259 
Cross, D. A., Alessi, D. R., Cohen, P., Andjelkovich, M., and Hemmings, B. A. (1995). Inhibition of glycogen synthase kinase- 3 by insulin mediated by protein kinase B. Nature 378, 785-789. doi: 10.1038/378785a0

Cross, D. A., Alessi, D. R., Vandenheede, J. R., Mcdowell, H. E., Hundal, H. S., and Cohen, P. (1994). The inhibition of glycogen synthase kinase-3 by insulin or insulin-like growth factor 1 in the rat skeletal muscle cell line L6 is blocked by wortmannin, but not by rapamycin: evidence that wortmannin blocks activation of the mitogen-activated protein kinase pathway in L6 cells between Ras and Raf. Biochem. J. 303(Pt 1), 21-26.

Davies, B. R., Greenwood, H., Dudley, P., Crafter, C., Yu, D. H., Zhang, J., et al. (2012). Preclinical pharmacology of AZD5363, an inhibitor of AKT: pharmacodynamics, antitumor activity, and correlation of monotherapy activity with genetic background. Mol. Cancer Ther. 11, 873-887. doi: 10.1158/1535-7163.MCT-11-0824-T

Ding, Q., Xia, W., Liu, J. C., Yang, J. Y., Lee, D. F., Xia, J., et al. (2005). Erk associates with and primes GSK-3beta for its inactivation resulting in upregulation of beta-catenin. Mol. Cell 19, 159-170. doi: 10.1016/j.molcel.2005.06.009

Embi, N., Rylatt, D. B., and Cohen, P. (1980). Glycogen synthase kinase-3 from rabbit skeletal muscle. Separation from cyclic-AMP-dependent protein kinase and phosphorylase kinase. Eur. J. Biochem. 107, 519-527.

Forde, J. E., and Dale, T. C. (2007). Glycogen synthase kinase 3: a key regulator of cellular fate. Cell Mol. Life Sci. 64, 1930-1944. doi: 10.1007/s00018-007-7045-7

Frame, S., and Cohen, P. (2001). GSK3 takes centre stage more than 20 years after its discovery. Biochem. J. 359, 1-16. doi: 10.1042/0264-6021:3590001

Frame, S., Cohen, P., and Biondi, R. M. (2001). A common phosphate binding site explains the unique substrate specificity of GSK3 and its inactivation by phosphorylation. Mol. Cell 7, 1321-1327. doi: 10.1016/S1097-2765(01)00253-2

Gold, M. R., Ingham, R. J., Mcleod, S. J., Christian, S. L., Scheid, M. P., Duronio, V., et al. (2000). Targets of B-cell antigen receptor signaling: the phosphatidylinositol 3-kinase/Akt/glycogen synthase kinase-3 signaling pathway and the Rap1 GTPase. Immunol. Rev. 176, 47-68. doi: 10.1034/j.1600065X.2000.00601.x

Golpich, M., Amini, E., Hemmati, F., Ibrahim, N. M., Rahmani, B., Mohamed, Z., et al. (2015). Glycogen synthase kinase-3 beta (GSK-3beta) signaling: implications for Parkinson's disease. Pharmacol. Res. 97, 16-26. doi: 10.1016/j.phrs.2015.03.010

Grabinski, T. M., Kneynsberg, A., Manfredsson, F. P., and Kanaan, N. M. (2015). A method for combining RNAscope in situ hybridization with immunohistochemistry in thick free-floating brain sections and primary neuronal cultures. PLoS ONE 10:e0120120. doi: 10.1371/journal.pone.0120120

Guichard, G., Benkirane, N., Zeder-Lutz, G., Van Regenmortel, M. H., Briand, J. P., and Muller, S. (1994). Antigenic mimicry of natural L-peptides with retro-inverso-peptidomimetics. Proc. Natl. Acad. Sci. U.S.A. 91, 9765-9769. doi: 10.1073/pnas.91.21.9765

Hagen, T., and Vidal-Puig, A. (2002). Characterisation of the phosphorylation of beta-catenin at the GSK-3 priming site Ser45. Biochem. Biophys. Res. Commun. 294, 324-328. doi: 10.1016/S0006-291X(02)00485-0

Hernandez, F., and Avila, J. (2008). The role of glycogen synthase kinase 3 in the early stages of Alzheimers' disease. FEBS Lett. 582, 3848-3854. doi: 10.1016/j.febslet.2008.10.026

Hetman, M., Cavanaugh, J. E., Kimelman, D., and Xia, Z. (2000). Role of glycogen synthase kinase-3beta in neuronal apoptosis induced by trophic withdrawal. J. Neurosci. 20, 2567-2574.

Hughes, K., Nikolakaki, E., Plyte, S. E., Totty, N. F., and Woodgett, J. R. (1993). Modulation of the glycogen synthase kinase- 3 family by tyrosine phosphorylation. EMBO J. 12, 803-808.

Hur, E. M., and Zhou, F. Q. (2010). GSK3 signalling in neural development. Nat. Rev. Neurosci. 11, 539-551. doi: 10.1038/nrn2870

Ishihara, H., Martin, B. L., Brautigan, D. L., Karaki, H., Ozaki, H., Kato, Y., et al. (1989). Calyculin A and okadaic acid: inhibitors of protein phosphatase activity. Biochem. Biophys. Res. Commun. 159, 871-877. doi: 10.1016/0006291X(89)92189-X

Kanaan, N. M., Cox, K., Alvarez, V. E., Stein, T. D., Poncil, S., and Mckee, A. C. (2016). Characterization of early pathological tau conformations and phosphorylation in chronic traumatic encephalopathy. J. Neuropathol. Exp. Neurol. 75, 19-34. doi: 10.1093/jnen/nlv001

Kanaan, N. M., Morfini, G., Pigino, G., Lapointe, N. E., Andreadis, A., Song, Y., et al. (2012). Phosphorylation in the amino terminus of tau prevents inhibition of anterograde axonal transport. Neurobiol. Aging 33, 886.e15-30. doi: 10.1016/j.neurobiolaging.2011.06.006

Kanaan, N. M., Morfini, G. A., Lapointe, N. E., Pigino, G. F., Patterson, K. R., Song, Y., et al. (2011). Pathogenic forms of tau inhibit kinesindependent axonal transport through a mechanism involving activation of axonal phosphotransferases. J. Neurosci. 31, 9858-9868. doi: 10.1523/JNEUROSCI.0560-11.2011

Kim, L., and Kimmel, A. R. (2006). GSK3 at the edge: regulation of developmental specification and cell polarization. Curr. Drug Targets 7, 1411-1419. doi: 10.2174/1389450110607011411

Kim, Y., Lee, Y. I., Seo, M., Kim, S. Y., Lee, J. E., Youn, H. D., et al. (2009). Calcineurin dephosphorylates glycogen synthase kinase- 3 beta at serine- 9 in neuroblast-derived cells. J. Neurochem. 111, 344-354. doi: 10.1111/j.14714159.2009.06318.x

Kockeritz, L., Doble, B., Patel, S., and Woodgett, J. R. (2006). Glycogen synthase kinase-3-an overview of an over-achieving protein kinase. Curr. Drug Targets 7, 1377-1388. doi: 10.2174/1389450110607011377

Lal, H., Ahmad, F., Woodgett, J., and Force, T. (2015). The GSK-3 family as therapeutic target for myocardial diseases. Circ. Res. 116, 138-149. doi: 10.1161/CIRCRESAHA.116.303613

Lee, Y. I., Seo, M., Kim, Y., Kim, S. Y., Kang, U. G., Kim, Y. S., et al. (2005). Membrane depolarization induces the undulating phosphorylation/dephosphorylation of glycogen synthase kinase 3beta, and this dephosphorylation involves protein phosphatases $2 \mathrm{~A}$ and $2 \mathrm{~B}$ in SH-SY5Y human neuroblastoma cells. J. Biol. Chem. 280, 22044-22052.

Leung-Hagesteijn, C., Mahendra, A., Naruszewicz, I., and Hannigan, G. E. (2001). Modulation of integrin signal transduction by ILKAP, a protein phosphatase $2 \mathrm{C}$ associating with the integrin-linked kinase, ILK1. EMBO J. 20, 2160-2170. doi: 10.1093/emboj/20.9.2160

Li, B., Thrasher, J. B., and Terranova, P. (2015). Glycogen synthase kinase-3: a potential preventive target for prostate cancer management. Urol. Oncol. 33, 456-463. doi: 10.1016/j.urolonc.2015.05.006

Li, J., Davies, B. R., Han, S., Zhou, M., Bai, Y., Zhang, J., et al. (2013). The AKT inhibitor AZD5363 is selectively active in PI3KCA mutant gastric cancer, and sensitizes a patient-derived gastric cancer xenograft model with PTEN loss to Taxotere. J. Transl. Med. 11:241. doi: 10.1186/1479-5876-11-241

Li, T., Hawkes, C., Qureshi, H. Y., Kar, S., and Paudel, H. K. (2006). Cyclindependent protein kinase 5 primes microtubule-associated protein tau sitespecifically for glycogen synthase kinase 3beta. Biochemistry 45, 3134-3145. doi: 10.1021/bi051635j

Lochhead, P. A., Kinstrie, R., Sibbet, G., Rawjee, T., Morrice, N., and Cleghon, V. (2006). A chaperone-dependent GSK3beta transitional intermediate mediates activation-loop autophosphorylation. Mol. Cell 24, 627-633. doi: 10.1016/j.molcel.2006.10.009

Ma, S., Liu, S., Huang, Q., Xie, B., Lai, B., Wang, C., et al. (2012). Sitespecific phosphorylation protects glycogen synthase kinase-3beta from calpainmediated truncation of its N and C termini. J. Biol. Chem. 287, 22521-22532. doi: 10.1074/jbc.M111.321349

Majewska, E., and Szeliga, M. (2016). AKT/GSK3beta Signaling in Glioblastoma. Neurochem. Res. 27, 1-7.

McManus, E. J., Sakamoto, K., Armit, L. J., Ronaldson, L., Shpiro, N., Marquez, R., et al. (2005). Role that phosphorylation of GSK3 plays in insulin and Wnt signalling defined by knockin analysis. EMBO J. 24, 1571-1583. doi: 10.1038/sj.emboj.7600633

Medina, M., and Wandosell, F. (2011). Deconstructing GSK-3: the fine regulation of its activity. Int. J. Alzheimers Dis. 2011:479249.

Millward, T. A., Zolnierowicz, S., and Hemmings, B. A. (1999). Regulation of protein kinase cascades by protein phosphatase 2A. Trends Biochem. Sci. 24, 186-191. doi: 10.1016/S0968-0004(99)01375-4

Morfini, G., Szebenyi, G., Brown, H., Pant, H. C., Pigino, G., Deboer, S., et al. (2004). A novel CDK5-dependent pathway for regulating GSK3 activity and kinesin-driven motility in neurons. EMBO J. 23, 2235-2245. doi: 10.1038/sj.emboj.7600237

O'Leary, O., and Nolan, Y. (2015). Glycogen synthase kinase-3 as a therapeutic target for cognitive dysfunction in neuropsychiatric disorders. CNS Drugs 29 , 1-15. doi: 10.1007/s40263-014-0213-Z

Resjo, S., Oknianska, A., Zolnierowicz, S., Manganiello, V., and Degerman, E. (1999). Phosphorylation and activation of phosphodiesterase type 3B (PDE3B) 
in adipocytes in response to serine/threonine phosphatase inhibitors: deactivation of PDE3B in vitro by protein phosphatase type 2A. Biochem. J. 341(Pt 3), 839-845. doi: 10.1042/bj3410839

Rylatt, D. B., Aitken, A., Bilham, T., Condon, G. D., Embi, N., and Cohen, P. (1980). Glycogen synthase from rabbit skeletal muscle. Amino acid sequence at the sites phosphorylated by glycogen synthase kinase-3, and extension of the $\mathrm{N}$-terminal sequence containing the site phosphorylated by phosphorylase kinase. Eur. J. Biochem. 107, 529-537. doi: 10.1111/j.1432-1033.1980.tb06060.x

Saitoh, M., Kunitomo, J., Kimura, E., Iwashita, H., Uno, Y., Onishi, T., et al. (2009). 2-\{3-[4-(Alkylsulfinyl)phenyl]-1-benzofuran-5-yl\}-5-methyl-1,3,4-oxadiazole derivatives as novel inhibitors of glycogen synthase kinase-3beta with good brain permeability. J. Med. Chem. 52, 6270-6286. doi: 10.1021/jm900647e

Sutherland, C. (2011). What are the bona fide GSK3 substrates? Int. J. Alzheimers Dis. 2011:505607.

Sutherland, C., Leighton, I. A., and Cohen, P. (1993). Inactivation of glycogen synthase kinase- 3 beta by phosphorylation: new kinase connections in insulin and growth-factor signalling. Biochem. J. 296, 15-19. doi: 10.1042/bj2960015

Szatmari, E., Habas, A., Yang, P., Zheng, J. J., Hagg, T., and Hetman, M. (2005). A positive feedback loop between glycogen synthase kinase 3 beta and protein phosphatase 1 after stimulation of NR2B NMDA receptors in forebrain neurons. J. Biol. Chem. 280, 37526-37535.

Thornton, T. M., Pedraza-Alva, G., Deng, B., Wood, C. D., Aronshtam, A., Clements, J. L., et al. (2008). Phosphorylation by p38 MAPK as an alternative pathway for GSK3beta inactivation. Science 320, 667-670. doi: $10.1126 /$ science. 1156037

Varea, O., Arevalo, M. A., Garrido, J. J., Garcia-Segura, L. M., Wandosell, F., and Mendez, P. (2010). Interaction of estrogen receptors with insulin-like growth factor-I and Wnt signaling in the nervous system. Steroids 75, 565-569. doi: 10.1016/j.steroids.2009.09.006
Wang, Q. M., Fiol, C. J., Depaoli-Roach, A. A., and Roach, P. J. (1994a). Glycogen synthase kinase-3 beta is a dual specificity kinase differentially regulated by tyrosine and serine/threonine phosphorylation. J. Biol. Chem. 269, 1456614574.

Wang, Q. M., Park, I. K., Fiol, C. J., Roach, P. J., and Depaoli-Roach, A. A. (1994b). Isoform differences in substrate recognition by glycogen synthase kinases 3 alpha and 3 beta in the phosphorylation of phosphatase inhibitor 2 . Biochemistry 33, 143-147. doi: 10.1021/bi00167a018

Welsh, G. I., Patel, J. C., and Proud, C. G. (1997). Peptide substrates suitable for assaying glycogen synthase kinase-3 in crude cell extracts. Anal. Biochem. 244, 16-21. doi: 10.1006/abio.1996.9838

Xiao, L., Gong, L. L., Yuan, D., Deng, M., Zeng, X. M., Chen, L. L., et al. (2010). Protein phosphatase-1 regulates Akt1 signal transduction pathway to control gene expression, cell survival and differentiation. Cell Death Differ. 17, 1448-1462. doi: 10.1038/cdd.2010.16

Zhang, W., Depaoli-Roach, A. A., and Roach, P. J. (1993). Mechanisms of multisite phosphorylation and inactivation of rabbit muscle glycogen synthase. Arch. Biochem. Biophys. 304, 219-225. doi: 10.1006/abbi.1993.1342

Conflict of Interest Statement: The authors declare that the research was conducted in the absence of any commercial or financial relationships that could be construed as a potential conflict of interest.

Copyright (c) 2016 Grabinski and Kanaan. This is an open-access article distributed under the terms of the Creative Commons Attribution License (CC BY). The use, distribution or reproduction in other forums is permitted, provided the original author(s) or licensor are credited and that the original publication in this journal is cited, in accordance with accepted academic practice. No use, distribution or reproduction is permitted which does not comply with these terms. 